\title{
Two-Dimensional Streamflow Simulations of the Jordan River, Midvale and West Jordan, Utah
}

Prepared in cooperation with the U.S. Environmental Protection Agency

Scientific Investigations Report 2011-5043 
Cover: Photographs showing upstream view of Jordan River near Midvale Slag site showing rock rip-rap on bank; view looking east across Jordan River at completed geo-technical cap at Midvale Slag site (photo provided by U.S. Environmental Protection Agency); upstream view of Jordan River near Sharon Steel site. 


\section{Two-Dimensional Streamflow Simulations of the Jordan River, Midvale and West Jordan, Utah}

By Terry A. Kenney and Michael L. Freeman

Prepared in cooperation with the U.S. Environmental Protection Agency

Scientific Investigations Report 2011-5043 


\title{
U.S. Department of the Interior \\ KEN SALAZAR, Secretary \\ U.S. Geological Survey \\ Marcia K. McNutt, Director
}

\section{U.S. Geological Survey, Reston, Virginia: 2011}

\author{
For more information on the USGS — the Federal source for science about the Earth, its natural and living resources, \\ natural hazards, and the environment, visit http://www.usgs.gov or call 1-888-ASK-USGS \\ For an overview of USGS information products, including maps, imagery, and publications, \\ visit http://www.usgs.gov/pubprod \\ To order this and other USGS information products, visit http://store.usgs.gov
}

Any use of trade, product, or firm names is for descriptive purposes only and does not imply endorsement by the U.S. Government.

Although this report is in the public domain, permission must be secured from the individual copyright owners to reproduce any copyrighted materials contained within this report.

Suggested citation:

Kenney, T.A., Freeman, M.L., 2011, Two-dimensional streamflow simulations of the Jordan River, Midvale and West Jordan, Utah: U.S. Geological Survey Scientific Investigations Report 2011-5043, 39 p. 


\section{Contents}

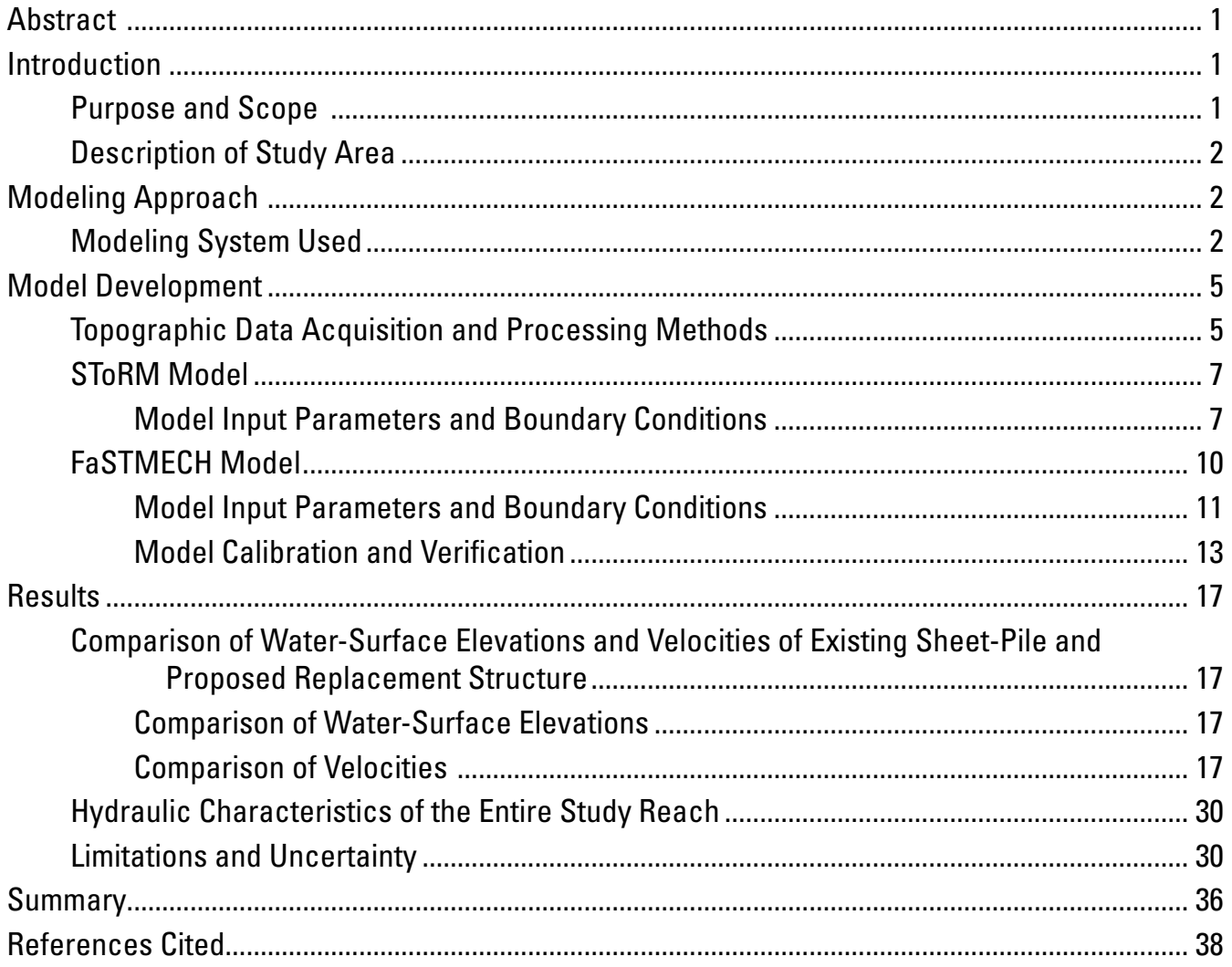

\section{Figures}

1. Map showing Jordan River study reach, Midvale and West Jordan, Utah 3

2. Map showing historic locations of the Jordan River in the study reach from previous river surveys, Midvale and West Jordan, Utah ................................................... 4

3. Photograph of left bank of the Jordan River showing Midvale Slag Superfund Site geotechnical cap ................................................................................................. 5

4. Photograph of existing sheet-pile dam ................................................................. 5

5. Map showing locations of survey data for the Jordan River study reach, Midvale and West Jordan, Utah

6. Photographs showing $A$, Unstructured grid and constraint line at the location of the existing sheet-pile dam, $B$, Model generated topography representing the existing sheet-pile dam.....

7. Photograph showing model generated topography of proposed replacement structure

8. Graph showing water-surface profiles for streamflows of 500 and 1,000 cubic feet per second associated with channel slopes of $0.0010,0.0015$, and 0.0020 foot per foot 
9. Map showing location of cross section velocity measurements, Midvale and West Jordan, Utah 14

10. Graph showing observed and predicted water-surface elevations for a streamflow of 1,100 cubic feet per second

11. Graphs showing relation between observed and predicted velocities for a streamflow of 1,100 cubic feet per second at eight cross sections in the Jordan River, Midvale and West Jordan, Utah

12. Map showing predicted water-surface elevations for the proposed replacement structure as designed minus predicted water-surface elevations for the existing sheet-pile dam for a streamflow of 500 cubic feet per second

13. Map showing predicted water-surface elevations for the proposed replacement structure with an increased topography of 1.0 foot minus predicted water-surface elevations for the existing sheet-pile dam for a streamflow of 500 cubic feet per second

14. Map showing predicted water-surface elevations for the proposed replacement structure with an increased topography of 2.0 feet minus predicted water-surface elevations for the existing sheet-pile dam for a streamflow of 500 cubic feet per second

15. Map showing predicted water-surface elevations for the proposed replacement structure as designed minus predicted water-surface elevations for the existing sheet-pile dam for a streamflow of 1,000 cubic feet per second

16. Map showing predicted water-surface elevations for the proposed replacement structure with an increased topography of 1.0 foot minus predicted water-surface elevations for the existing sheet-pile dam for a streamflow of 1,000 cubic feet per second

17. Map showing predicted water-surface elevations for the proposed replacement structure with an increased topography of 2.0 feet minus predicted water-surface elevations for the existing sheet-pile dam for a streamflow of 1,000 cubic feet per second

18. Map showing predicted water velocities for the proposed replacement structure as designed minus predicted water velocities for the existing sheet-pile dam for a streamflow of 500 cubic feet per second

19. Map showing predicted water velocities for the proposed replacement structure with an increased topography of 1.0 foot minus predicted water velocities for the existing sheet-pile dam for a streamflow of 500 cubic feet per second

20. Map showing predicted water velocities for the proposed replacement structure with an increased topography of 2.0 feet minus predicted water velocities for the existing sheet-pile dam for a streamflow of 500 cubic feet per second

21. Map showing predicted water velocities for the proposed replacement structure as designed minus predicted water velocities for the existing sheet-pile dam for a streamflow of 1,000 cubic feet per second

22. Map showing predicted water velocities for the proposed replacement structure with an increased topography of 1.0 foot minus predicted water velocities for the existing sheet-pile dam for a streamflow of 1,000 cubic feet per second

23. Map showing predicted water velocities for the proposed replacement structure with an increased topography of 2.0 feet minus predicted water velocities for the existing sheet-pile dam for a streamflow of 1,000 cubic feet per second

24. Map showing predicted water-surface elevations throughout the study reach for a streamflow of 2,790 cubic feet per second 
25. Map showing predicted water velocities throughout the study reach for a streamflow of 2,790 cubic feet per second 32

26. Map showing predicted boundary shear stress throughout the study reach for a streamflow of 2,790 cubic feet per second

27. A, map showing model predicted boundary shear stress near constructed sheet-pile dam replacement structure for a streamflow of 1,100 cubic feet per second. $B$, photograph taken upstream from constructed sheet-pile dam replacement structure looking downstream at rock riprap along east bank of Jordan River at a streamflow of 1,100 cubic feet per second

28. Map showing close-up of structured curvilinear grid overlaid on an aerial photograph showing how the cross-stream node strings are perpendicular to the direction of flow

29. Graph showing downstream profile of predicted cross-stream maximum and average velocities for a streamflow of 1,040 cubic feet per second

30. Graph showing downstream profile of predicted cross-stream maximum and average velocities for a streamflow of 2,790 cubic feet per second

31. Graph showing downstream profile of predicted cross-stream average watersurface elevations for streamflows of 1,040 and 2,790 cubic feet per second. Average channel-bed elevations also are shown

\section{Tables}

1. Selected model parameters for SToRM model simulations

2. Select model parameters for FaSTMECH model simulations

\section{Conversion Factors}

Inch/Pound to SI

\begin{tabular}{|c|c|c|}
\hline Multiply & By & To obtain \\
\hline \multicolumn{3}{|c|}{ Length } \\
\hline foot $(\mathrm{ft})$ & 0.3048 & meter $(\mathrm{m})$ \\
\hline mile (mi) & 1.609 & kilometer $(\mathrm{km})$ \\
\hline \multicolumn{3}{|c|}{ Area } \\
\hline acre & 4,047 & square meter $\left(\mathrm{m}^{2}\right)$ \\
\hline square foot $\left(\mathrm{ft}^{2}\right)$ & 0.0929 & square meter $\left(\mathrm{m}^{2}\right)$ \\
\hline \multicolumn{3}{|c|}{ Flow rate } \\
\hline cubic foot per second $\left(\mathrm{ft}^{3} / \mathrm{s}\right)$ & 0.0929 & cubic meter per second $\left(\mathrm{m}^{3} / \mathrm{s}\right)$ \\
\hline \multicolumn{3}{|c|}{ Pressure } \\
\hline pound per square foot $\left(\mathrm{lb} / \mathrm{ft}^{2}\right)$ & 0.04788 & kilopascal $(\mathrm{kPa})$ \\
\hline
\end{tabular}

Vertical coordinate information is referenced to the North American Vertical Datum of 1988 (NAVD 88).

Horizontal coordinate information is referenced to the North American Datum of 1983 (NAD 83). 



\title{
Two-Dimensional Streamflow Simulations of the Jordan River, Midvale and West Jordan, Utah
}

\author{
By Terry A. Kenney and Michael L. Freeman
}

\section{Abstract}

The Jordan River in Midvale and West Jordan, Utah, flows adjacent to two U.S. Environmental Protection Agency Superfund sites: Midvale Slag and Sharon Steel. At both sites, geotechnical caps extend to the east bank of the river. The final remediation tasks for these sites included the replacement of a historic sheet-pile dam and the stabilization of the river banks adjacent to the Superfund sites. To assist with these tasks, two hydraulic modeling codes contained in the U.S. Geological Survey (USGS) Multi-Dimensional Surface-Water Modeling System (MD_SWMS), System for Transport and River Modeling (SToRM) and Flow and Sediment Transport and Morphological Evolution of Channels (FaSTMECH), were used to provide predicted water-surface elevations, velocities, and boundary shear-stress values throughout the study reach of the Jordan River. A SToRM model of a 0.7 mile (mi) subreach containing the sheet-pile dam was used to compare watersurface elevations and velocities associated with the sheet-pile dam and a proposed replacement structure. Maps showing water-surface elevation and velocity differences computed from simulations of the historic sheet-pile dam and the proposed replacement structure topographies for streamflows of 500 and 1,000 cubic feet per second $\left(\mathrm{ft}^{3} / \mathrm{s}\right)$ were created. These difference maps indicated that the velocities associated with the proposed replacement structure topographies were less than or equal to those associated with the historic sheetpile dam. Similarly, water-surface elevations associated with the proposed replacement structure topographies were all either greater than or equal to water-surface elevations associated with the sheet-pile dam. A FaSTMECH model was developed for the 2.5-mile study reach to aid engineers in bank stabilization designs. Predicted water-surface elevations, velocities and shear-stress values were mapped on an aerial photograph of the study reach to place these parameters in a spatial context. Profile plots of predicted cross-stream average water-surface elevations and cross-stream maximum and average velocities showed how these parameters change along the study reach for two simulated discharges of $1,040 \mathrm{ft}^{3} / \mathrm{s}$ and $2,790 \mathrm{ft}^{3} / \mathrm{s}$. The profile plots for the simulated streamflow of $1,040 \mathrm{ft}^{3} / \mathrm{s}$ show that the highest velocities are associated with the constructed sheet-pile replacement structure.
Results for the simulated streamflow of $2,790 \mathrm{ft}^{3} / \mathrm{s}$ indicate that the geometry of the 7800 South Bridge causes more backwater and higher velocities than the constructed sheet-pile replacement structure.

\section{Introduction}

The Jordan River in Midvale and West Jordan, Utah, flows adjacent to two reclaimed U.S. Environmental Protection Agency (USEPA) Superfund sites: Midvale Slag and Sharon Steel. Remediation of these two sites included onsite geotechnical capping of more than 12 million tons of smelting and mine-waste materials. These sites have been zoned for mixed-use residential, commercial, and open space. At both sites, the reclaimed area extends to the east bank of the Jordan River, which required the USEPA to ensure that the banks were protected from erosion associated with streamflows in the Jordan River. A historic sheet-pile dam, which acted as the hydraulic control for a length of the reach as determined through hydraulic modeling, was removed and replaced. In support of the efforts of the USEPA to stabilize the engineered banks and to replace the historic sheet-pile dam, the U.S. Geological Survey (USGS) constructed a series of twodimensional hydraulic models.

\section{Purpose and Scope}

This report documents the construction of multiple twodimensional hydraulic models of the Jordan River in Midvale and West Jordan, Utah in the vicinity of USEPA Superfund sites. The models were used to aid the USEPA in their final mitigation efforts of two Superfund sites. These models were developed for the specific tasks of removing and replacing a historic sheet-pile dam, and stabilization of the channel banks. The approach used to represent the topography of the study reach is described. Calibration and verification of the models are discussed along with the results. Limitations and uncertainty associated with the interpretation of the results generated by this study also are provided. 


\section{Description of Study Area}

The study reach of the Jordan River in Midvale and West Jordan, Utah, is approximately $2.5 \mathrm{mi}$ long and flows north from 9000 South to approximately $1,500 \mathrm{ft}$ north of the Union Pacific railroad crossing at the Midvale Slag site (fig. 1). The river flows north from 9000 South through pasture fields located near some industrial buildings prior to a near 90-degree turn to the west at the south end of the Sharon Steel site. At this turn the river is bounded on the north by the Sharon Steel site and the Jordan River Parkway Trail. On the north side of the parkway is a wetland. Prior to the establishment of the Sharon Steel complex, historic river surveys indicated that the course of the Jordan River traversed the current wetland and flowed towards the northwest through what is now the Sharon Steel site (CH2M Hill, written commun., 1992) (fig. 2). As the Sharon Steel complex expanded over the years it appears that the Jordan River was realigned to flow west at the south end of the property for approximately $0.3 \mathrm{mi}$ and then north along the western boundary towards 7800 South. It is along this realignment that the Jordan River now flows.

The northern boundary of the Sharon Steel Superfund Site is 7800 South, which also is the southern boundary of the Midvale Slag Superfund Site. Just south of 7800 South, the Jordan River Parkway Trail crosses the river and remains on the west side of the river throughout the remainder of the study reach. North of 7800 South the Midvale Slag Superfund Site is bounded on the west by the Jordan River. Different from the Sharon Steel Superfund Site, which is set back on the overbank area of the river, the geotechnical cap of the Midvale Slag site extends to the Jordan River and at many locations is the river's eastern bank (fig. 3).

North of 7800 South the river generally flows towards the north, with a few minor meanders. At the first meander towards the east is the location of the historic sheet-pile dam (fig. 4) which was used for the delivery of process water to the smelting and other operations of the Midvale Slag Superfund Site. When the USEPA became steward of the Midvale Slag Superfund Site, the sheet-pile dam was compromised, considered dangerous, and the USEPA slated it for removal as part of their final remediation efforts (Erna Waterman, U.S. Environmental Protection Agency, oral commun., 2008). Although in poor shape, the sheet pile remained as the active hydraulic control for most streamflows within the Midvale Slag subreach upstream to about the 7800 South Bridge.

The Jordan River in Salt Lake County is regulated heavily by releases from Utah Lake, located approximately $22 \mathrm{mi}$ upstream from the study reach. There are some drainages from the Oquirrh Mountains to the west and the Wasatch Mountains to the east that enter the Jordan River between Utah Lake and the study reach, but they are minor and contribute a small portion of the annual streamflow. The release of water from Utah Lake dominates the annual hydrograph of the Jordan River, and the amount of water released in a given year is dependent upon water rights and the amount of water available in Utah Lake. The average annual mean streamflow at Salt Lake County streamflow gaging station 150, Jordan River at 9000 South, is $398 \mathrm{ft}^{3} / \mathrm{s}$, computed from a period of record of 1981 through 2007. Generally, releases greater than $500 \mathrm{ft}^{3} / \mathrm{s}$ begin in April because of snowmelt runoff entering Utah Lake and continue into June. Throughout the summer, fall, and winter releases from Utah Lake are steady and generally small. Precipitation can cause rapid increases in streamflow up to about $300 \mathrm{ft}^{3} / \mathrm{s}$ during the summer through winter period, July through March.

\section{Modeling Approach}

Multi-dimensional hydraulic models are used to predict hydraulic characteristics, such as water-surface elevations and velocities, throughout the modeling domain at a user defined resolution. In complicated, or nonuniform riverine environments, such as those with flow direction changes or channel islands, two-dimensional hydraulic models can provide a more robust and meaningful solution than a onedimensional model. Two-dimensional hydraulic models provide a more detailed representation of the hydraulic characteristics of interest, most often velocity and watersurface elevation. These models provide a discrete distribution of the results at each of the computational nodes of the modeling domain. The two-dimensional solution allows for velocities to be presented in vector form with horizontal direction and magnitude. The length of the study reach together with the unique tasks of the remediation efforts required the development of a series of two-dimensional hydraulic models of differing lengths and scales.

\section{Modeling System Used}

Two modeling codes, System for Transport and River Modeling (SToRM) and Flow and Sediment Transport and Morphological Evolution of Channels (FaSTMECH), which are contained within the USGS Multi-Dimensional Surface Water Modeling System (MD_SWMS), were used to address the various engineering questions associated with the Jordan River remediation efforts of the USEPA. MD_SWMS is a graphical user interface for applying these types of models that allows for, among other things, editing and visualizing of model input data, examining model output, and both visual and statistical evaluation of observed and predicted parameters (McDonald and others, 2005).

SToRM is a finite volume surface-water flow model that simulates vertically averaged two-dimensional streamflow velocities. SToRM uses an unstructured grid to represent the modeling domain, which allows for localized grid refinement and constraints. SToRM possesses both steady and unsteady flow functionality, and can deal with subcritical and supercritical flows and flow regime transitions, such as hydraulic jumps (Simões, 2009). 


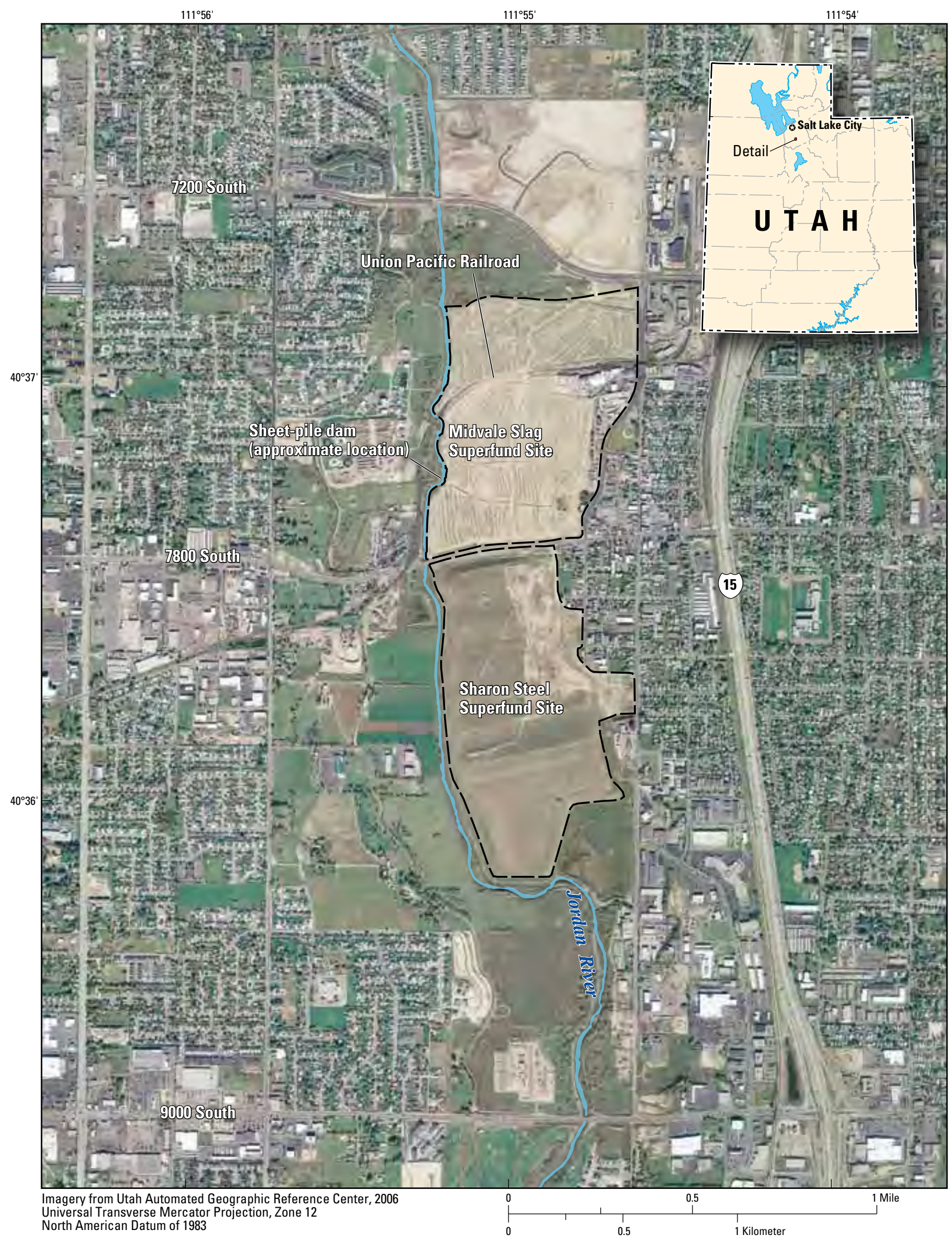

Figure 1. Jordan River study reach, Midvale and West Jordan, Utah. 


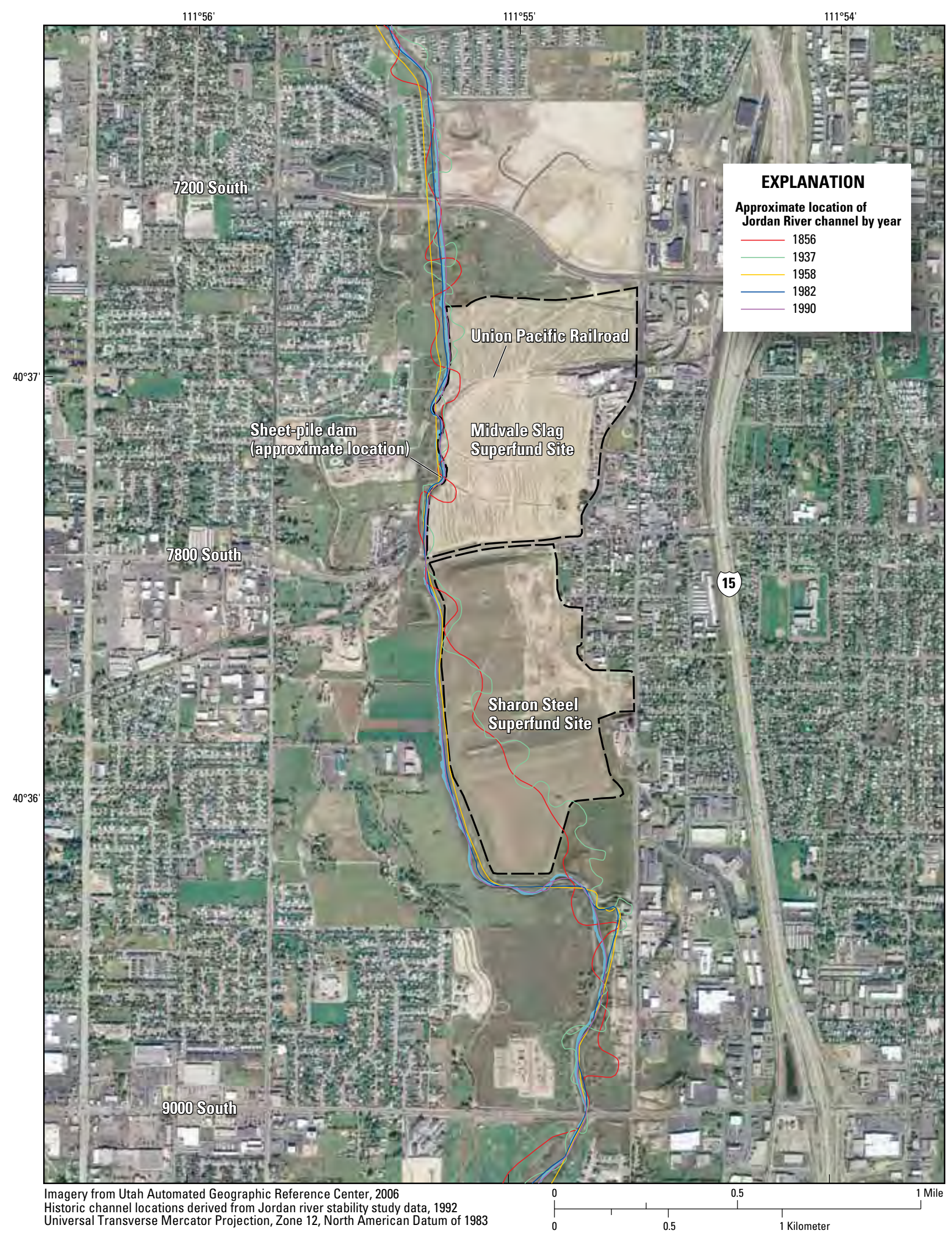

Figure 2. Historic locations of the Jordan River in the study reach from previous river surveys, Midvale and West Jordan, Utah. 


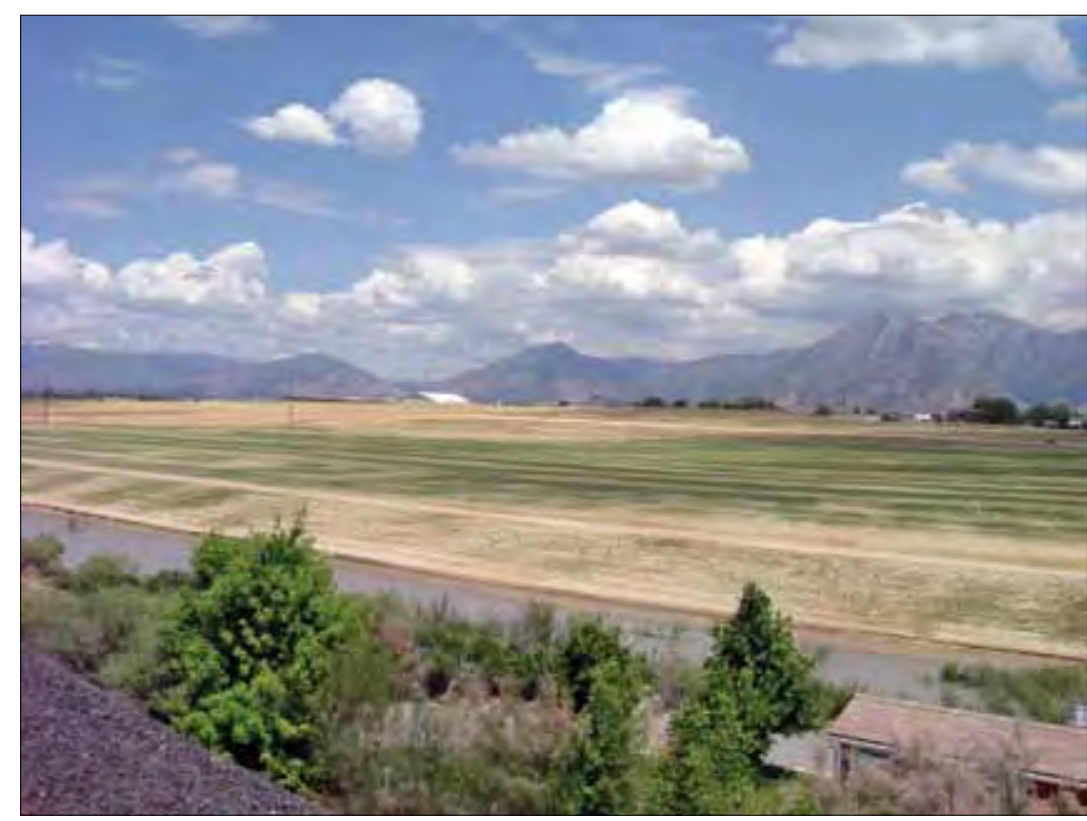

Figure 3. Left bank of the Jordan River showing Midvale Slag Superfund Site geotechnical cap. Photograph provided by U.S. Environmental Protection Agency.
FaSTMECH is a finite-element, steadystate surface-water flow model that simulates vertically averaged two- and two and onehalf-dimensional streamflow velocities based on input parameters and boundary conditions. Input parameters include surface topography and surface-material roughness, which are input as nondimensional drag coefficients. Boundary conditions consist of discharge at the upstream boundary and water-surface elevation at the downstream boundary. The model boundary is defined by the creation of a structured curvilinear grid in which the number of streamwise and cross-stream points are defined by the user.

\section{Model Development}

Models were constructed for the Jordan River study reach using both the SToRM and FaSTMECH modeling codes within MD SWMS. A high priority of the USEPA was the removal and replacement of the historic sheetpile dam associated with the Midvale Slag site. SToRM was chosen to examine the hydraulic characteristics of the sheetpile dam and the proposed replacement structure because of its unstructured grid and multiflow regime capabilities. A FaSTMECH model of the entire 2.5-mi study reach was developed to assess bank stabilization aspects of the mitigation of the two USEPA Superfund sites.

\section{Topographic Data Acquisition and Processing Methods}

The topographic representation of the Jordan River study reach that was used in the hydraulic models was developed from more than 2,500 unique bathymetric survey points (fig. 5) meshed with available 6.56-ft (2-m) resolution Light Detection and Ranging (LIDAR) data (Utah Automated Geographic Reference Center, 2008). Bathymetric survey data of the active river channel and banks were acquired manually using a real-time kinematic global positioning system (RTKGPS) in February 2008. RTK-GPS allows for precise and rapid acquisition of real-world coordinate and elevation data. More than 90 target cross sections were identified prior to the survey and were delineated digitally to guide the survey in the field.

Horizontal and vertical coordinate data surveyed with the RTK-GPS were collected relative to a portable base-station setup over two newly established stable reference points with unknown survey control in the Midvale area. For each reference point, continuous location data were logged by the base station for more than 4 hours. Following data collection, the logged base station data were processed by the National

Figure 4. Existing sheet-pile dam. 


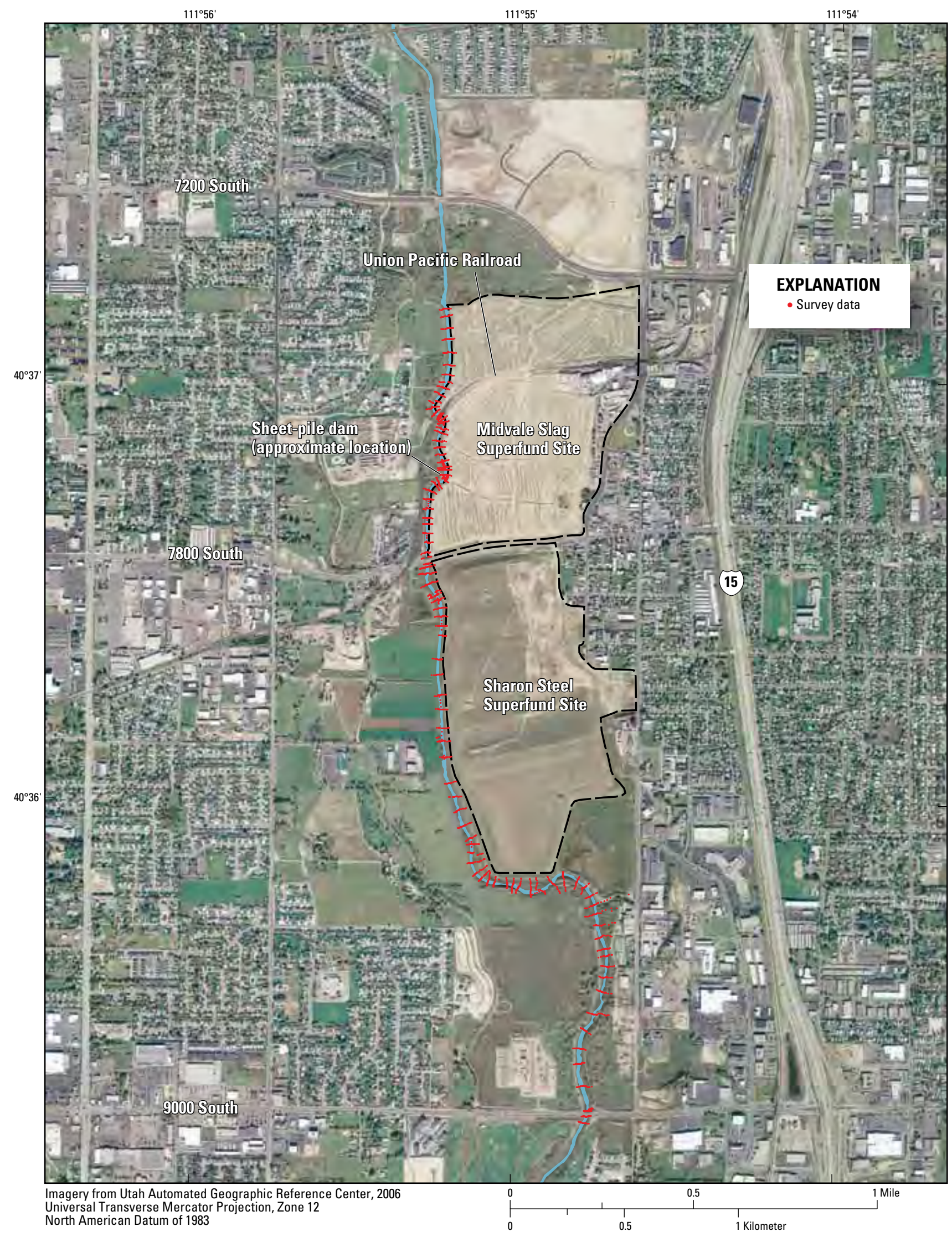

Figure 5. Locations of survey data for the Jordan River study reach, Midvale and West Jordan, Utah. 
Geodetic Survey (NGS) Online Positioning User Service (OPUS) to obtain a precise location and elevation solution for each base-station setup using the NGS National Spatial Reference System (NSRS). Absolute horizontal position accuracies for the two base-station locations, as reported from OPUS, ranged from 0.036 to $0.102 \mathrm{ft}$, and absolute vertical position accuracies ranged from 0.095 to $0.112 \mathrm{ft}$. Survey data collected relative to the base station with the RTK-GPS rover have a manufacturer reported accuracy of $+0.033 \mathrm{ft}+1$ part per million (ppm) in the horizontal and $+0.066+1 \mathrm{ppm}$ in the vertical direction (Trimble Navigation Limited, 2001). After the precise solutions were determined for the two base-station setups, associated adjustments were applied to the survey points. All elevations are orthometric heights converted from ellipsoid heights using the geoid model GEOID03 (National Geodetic Survey, 2004).

The acquired survey points generally were collected as river-channel cross sections. Spacing between cross sections was on average less than $100 \mathrm{ft}$. While the surveyed cross sections were collected in a manner that accurately defined the river course, the stream-wise density of the cross sections was not high enough for the desired two-dimensional analysis. The resolution of the results of a two-dimensional hydraulic model is dependent on the resolution of the input topographic data. For example, if it was desired to predict water velocities every $6 \mathrm{ft}$, the topographic surface input into the model should be of a similar resolution. For these reasons, the river channel between the surveyed cross sections was interpolated manually with the aid of high resolution aerial photography from 2006 using the editing and interpolation tools of MD SWMS. Considerations were made for channel islands and various hydraulic structures, such as bridges and the historic sheet-pile dam located at the Midvale Slag site, which also were surveyed. To represent the unsurveyed overbank areas of the study reach, $6.56-\mathrm{ft}(2-\mathrm{m})$ resolution LIDAR data were used. Together, the interpolated river channel and the LIDAR data provided a continuous topographic surface that was satisfactory for input into the hydraulic models.

\section{SToRM Model}

The USEPA's first task of the remediation efforts associated with the Jordan River was the removal and replacement of the existing sheet-pile dam located at the Midvale Slag site. The existing sheet-pile dam was the hydraulic control in the Midvale Slag subreach for most streamflows. The USEPA's highest priority in this section of the river was to ensure that the geotechnical cap, which is the east bank of the river in many locations, was not susceptible to erosion by the Jordan River. Erosion from streamflows is related to shearing force which is a function of water velocity. With this priority in mind, the replacement structure was to be designed in a manner so that upstream water velocities would be less than or equal to water velocities associated with the existing sheet-pile dam. To achieve this, the water-surface elevation drop and related energy loss caused by the dam needed to be preserved by the replacement structure.

To properly assess the hydraulic characteristics of a replacement structure, it was first necessary to determine the existing hydraulic conditions of the sheet-pile dam. A SToRM model was constructed for the Midvale Slag subreach beginning upstream from 7800 South and continuing downstream to approximately $600 \mathrm{ft}$ north of the Union Pacific Railroad Bridge (fig. 1). To define the Midvale Slag subreach model domain, an unstructured grid comprised of more than 5,300 nodes defined by triangles that were constrained to have a maximum area of about $65 \mathrm{ft}^{2}$ and minimum internal angles of 32.5 degrees was created (fig. $6 A$ ). The width of the unstructured grid measured perpendicular to the main channel ranged from 108 to $197 \mathrm{ft}$ and the total length as measured along the center of the channel was approximately $0.7 \mathrm{mi}$. A constraint line was input along the crest of the existing sheetpile dam, which was not a linear feature, to enforce its edge in the grid triangulation (fig. 6A). The resulting topography, which shows a rapid drop in elevation at the downstream end of the sheet-pile dam, is shown in figure $6 B$.

After constructing the SToRM model for the existing sheet-pile dam, the proposed replacement structure was examined with the model. A computer-aided design (CAD) of the proposed structure was provided by the USEPA. To allow for comparisons of the hydraulic characteristics of the existing sheet-pile dam with the proposed replacement structure, the existing sheet-pile dam SToRM model was replicated and the topography was adjusted. In the replicated model, the topography of the proposed structure replaced the existing dam in the same unstructured grid domain (fig. 7). The proposed structure was designed to gradually increase the channel-bed elevation to a crest elevation of about 4,277 $\mathrm{ft}$ and then gradually decrease it to meet the existing channel bed approximately $70 \mathrm{ft}$ downstream. The banks of the structure were designed to constrict the channel near the crest. The surface characteristics of the structure were designed to mimic the roughness of a natural channel by grouting in natural rock. This design was intended to provide similar hydraulic control as the sheet-pile dam without the dangerous drop associated with the sharp crest of the sheet piles. As part of the assessment, an effort was made to examine other configurations of the proposed structure by increasing the main channel elevations of the structure in $0.5 \mathrm{ft}$ increments up to $2.0 \mathrm{ft}$.

\section{Model Input Parameters and Boundary Conditions}

Streamflows of 500 and $1,000 \mathrm{ft}^{3} / \mathrm{s}$ were selected for simulation in the SToRM model to compare the hydraulic characteristics of the existing sheet-pile dam and the proposed replacement structure. As stated previously, the replacement structure was to be designed in a manner that upstream water velocities would be less than or equal to water velocities 

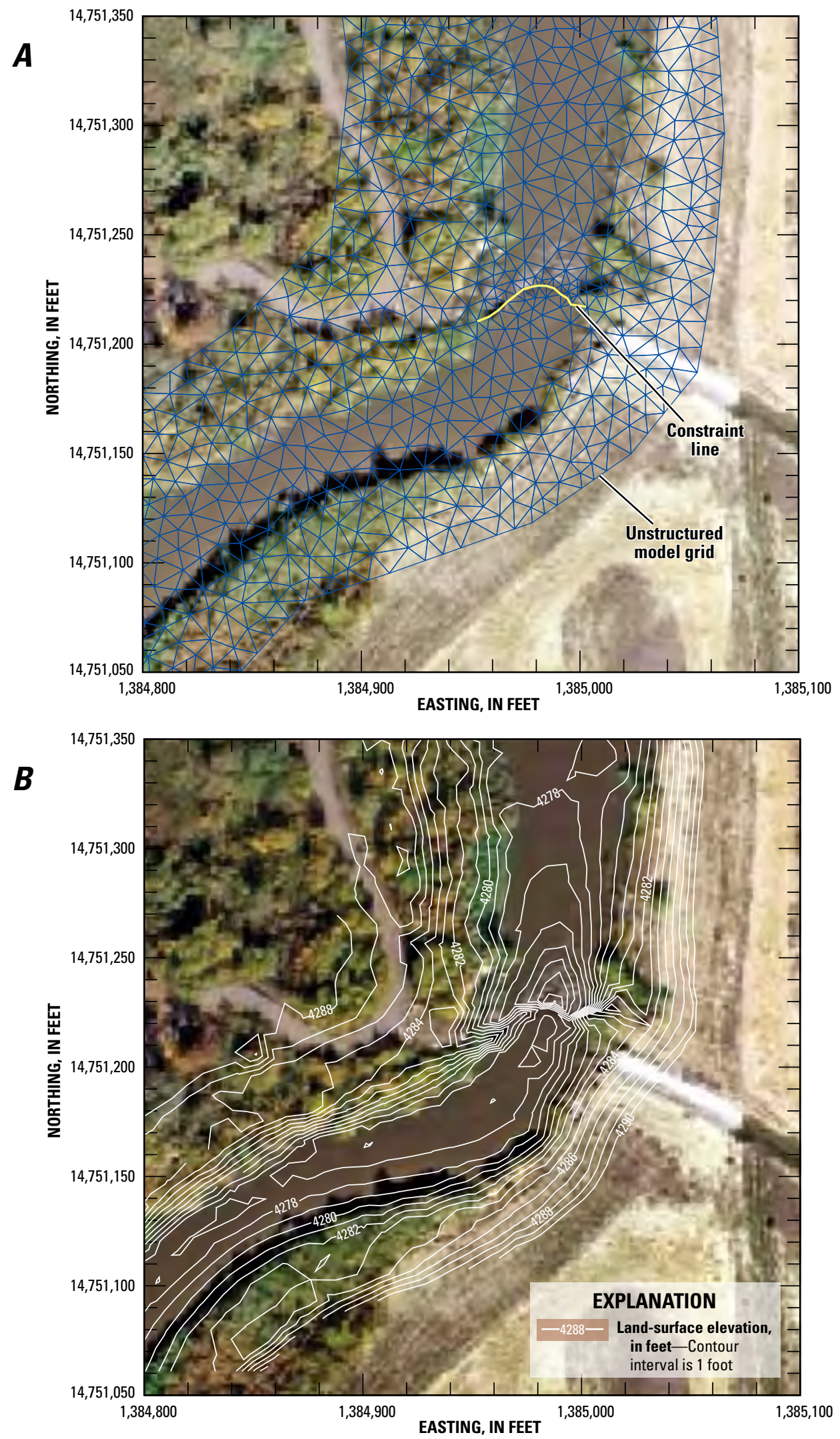

Figure 6. $\boldsymbol{A}$, Unstructured grid and constraint line at the location of the existing sheet-pile dam, $\boldsymbol{B}$, Model generated topography representing the existing sheet-pile dam. 


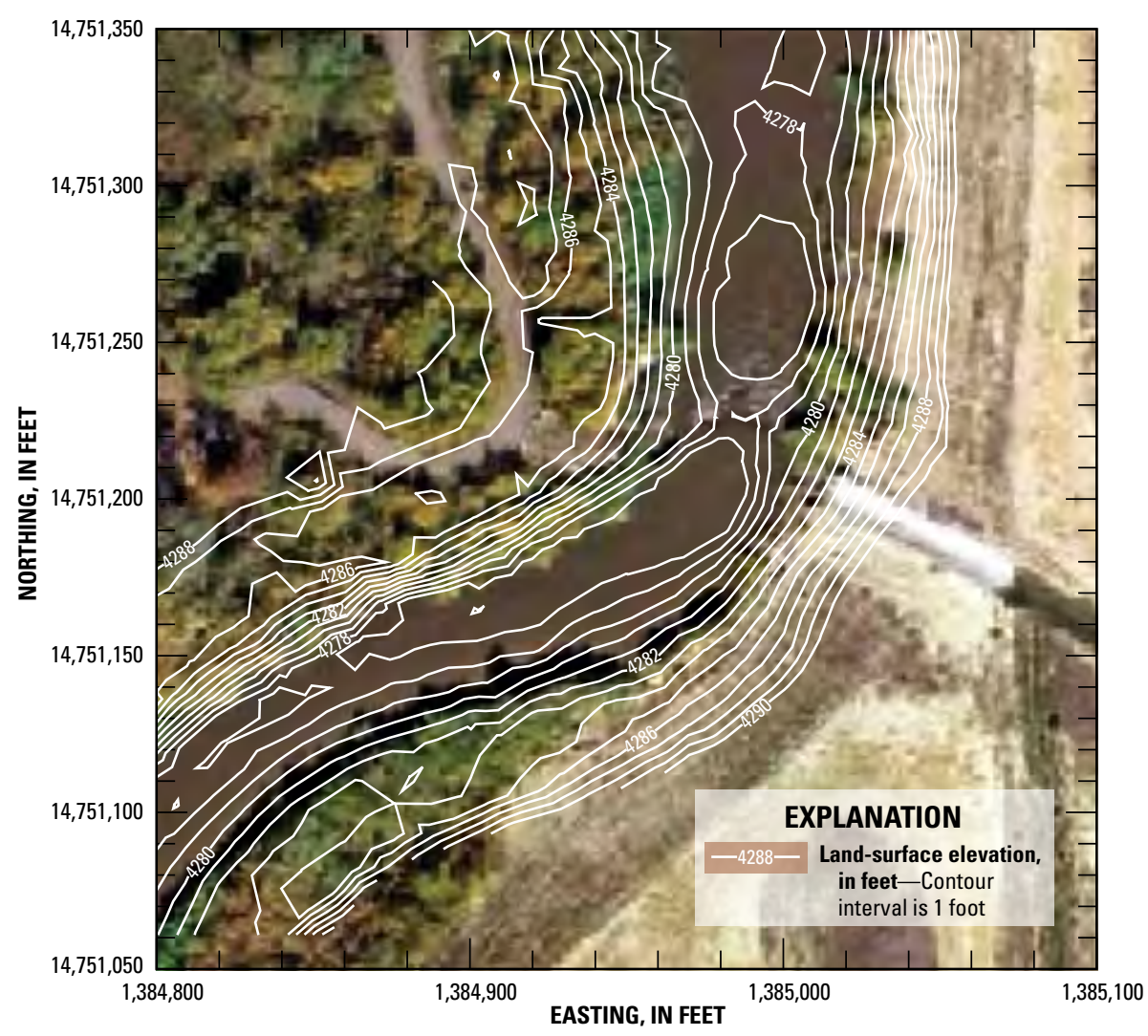

Figure 7. Model generated topography of proposed replacement structure.

associated with the existing sheet-pile dam. Understanding that high streamflows possess greater velocities than low streamflows, these two streamflows were selected to represent the type of high streamflows that occur in the heavily regulated Jordan River. The average annual maximum daily streamflow at Salt Lake County streamflow gaging station 150, Jordan River at 9000 South, is $850 \mathrm{ft}^{3} / \mathrm{s}$ (Salt Lake County Flood Control, 2010). The two selected streamflows, a medium-high and a high streamflow that are common to the study reach, bracket this average annual maximum and provided a good understanding of the hydraulic differences between the existing and proposed structures.

The conveyance of water in open channels is controlled by the physical characteristics of the channel including geometry, slope, and friction or roughness. Channel roughness is a measurement of the frictional characteristics of the bounding channel materials that cause energy losses in streamflow. Whereas geometry and slope are properties that are relatively easy to measure, roughness, when represented using a Manning's roughness coefficient, often changes with streamflow depth. SToRM allows for channel roughness to be represented through a variety of accepted methods including Manning's roughness coefficient, $n$. Channel roughness, in the form of $n$, was estimated to be 0.035 for the entire sheet-pile dam subreach on the basis of existing tables for specific materials (Chow, 1959) and comparison of study reach photographs with photographs of streams with determined roughness values (Barnes, 1967; Hicks and Mason, 1998; Phillips and Ingersoll, 1998). This value of $n$ was used for both simulated streamflows in all six SToRM model configurations (existing sheet-pile dam, proposed structure, and proposed structure elevation plus $0.5,1.0$, 1.5 , and $2.0 \mathrm{ft}$ ). Calibration and(or) verification data, such as observed water-surface elevations, which would be used to resolve the most representative Manning's roughness coefficient, were not available when the assessment of the existing and proposed structures was done. This assessment was concerned exclusively with differences in channel velocities and water-surface elevations associated with the different structure topographies, and the roughness characteristics of the proposed structure were designed to be similar to those of the Jordan River. For these reasons, dealing with a single Manning's roughness value for all streamflows and topographies is believed to have provided an efficient and responsible means for comparing hydraulic characteristics associated with the two different structures and six topographies. 
Upstream discharge and corresponding downstream boundary water-surface elevation are required input parameters for the SToRM model. Downstream water-surface elevations for the two streamflows of interest, 500 and 1,000 $\mathrm{ft}^{3} / \mathrm{s}$, were determined using the one-dimensional U.S. Army Corps of Engineers' (USACE) Hydrologic Engineering Center River Analysis System (HEC-RAS). After merging the interpolated channel topography and the overbank LIDAR data, discussed previously, these data were imported into ArcGIS (version 9.2, Environmental Systems Research Institute [ESRI], San Diego, California, written commun., 2008), and the USACE HEC-GeoRAS tool for ArcGIS was used to define 73 cross sections throughout the entire 2.5-mi study reach. These cross sections were then exported into HEC-RAS.

The water-surface elevation at the most downstream cross section was set at normal depth (Federal Emergency Management Agency, 2003) in HEC-RAS using a measured channel-bed slope downstream from the Union Pacific Railroad Bridge of $0.0015 \mathrm{ft} / \mathrm{ft}$. The streamflows of interest were then set at the upstream boundary. From these steadystate simulations, water-surface elevations for each of the 73 cross sections of the study reach were obtained by using the energy equation method used in HEC-RAS. Computed water-surface elevations at the cross section located at the downstream boundary of the SToRM model are shown in table 1.

The downstream boundary of the SToRM model was located approximately $2,860 \mathrm{ft}$ upstream from the most downstream cross section of the one-dimensional HEC-RAS model. HEC-RAS uses the step-backwater method to solve water-surface profiles, from which water-surface elevations are obtained at specific locations. The advantage of the stepbackwater method is that several water-surface profiles for the same streamflow are determined using different water-surface elevations at the downstream section that are derived, in the case of HEC-RAS, from different input slope values. These profiles determined from different water-surface elevations at the downstream section tend to converge to a single profile if the backwater computations are carried upstream through an adequate reach (Baily and Ray, 1966). To provide an assessment of the accuracies of the input SToRM model downstream boundary water-surface elevations, two other channel slopes, 0.0010 and $0.0020 \mathrm{ft} / \mathrm{ft}$, were input into the HEC-RAS model. Convergence of the water-surface profiles in the HEC-RAS simulations for the input channel slopes was examined (fig. 8). As shown, predicted water-surface elevations are shown to converge downstream of the SToRM model downstream boundary for the $500 \mathrm{ft}^{3} / \mathrm{s}$ simulation and just upstream from that boundary for the $1,000 \mathrm{ft}^{3} / \mathrm{s}$ simulation. Predicted water-surface elevations at the SToRM model downstream boundary for the three channel slopes have a maximum difference of $0.007 \mathrm{ft}$ for the $500 \mathrm{ft}^{3} / \mathrm{s}$ simulation and $0.046 \mathrm{ft}$ for the $1,000 \mathrm{ft}^{3} / \mathrm{s}$ simulation. The water-surface elevations determined from the measured channel-bed slope of $0.0015 \mathrm{ft} / \mathrm{ft}$ were used for the water-surface elevations at the SToRM model downstream boundary for both simulated streamflows. Manning's $n$ values for the cross sections of the HEC-RAS model were all set to 0.035 , the same values used in the SToRM model.

To execute a SToRM model and obtain a valid solution, there are a number of parameters that need to be properly set, which are dependent on various hydraulic characteristics of the stream reach being modeled. General guidelines or ranges for setting many of these parameters are available (Francisco Simões, U.S. Geological Survey, written commun. April 2010); however, achieving the optimal combination of parameter values for a given stream reach and streamflow is an iterative trial and error process. Initial values for the model parameters were selected using guidelines suggested for riverine environments similar to the Jordan River reach. These initial values were adjusted until stable and repeatable solutions were achieved. Pertinent final model parameters for the sheet-pile subreach SToRM models are shown in table 1. Aside from the 2 different streamflows and associated watersurface elevations, these parameters remained the same for each of the 12 simulations.

\section{FaSTMECH Model}

Mitigation goals of the USEPA along the riparian corridor of the Superfund sites included stabilizing the banks of the existing river channel. To facilitate the development of effective bank stabilization designs throughout the Jordan River study reach, a FaSTMECH model was constructed to provide water-surface elevations and velocities for a range of streamflows. Shear stress distributions, computed from the predicted velocities, also were provided.

It is important to note that the form of the constructed replacement structure differs significantly from the proposed structure that was examined using the SToRM model described above. The FaSTMECH model was constructed following the installation of the sheet-pile dam replacement structure and incorporates the topography of the new structure. The results provided by the FaSTMECH model are specific to the constructed sheet-pile dam replacement structure.

The FaSTMECH model domain of the study reach extends from 9000 South to approximately 1,500 ft north of the Union Pacific Railroad crossing (fig. 1) and was represented using a curvilinear orthogonal grid consisting of approximately 91,500 nodes. The grid, which generally followed the course of the river, was defined by 61 cross-stream and 1,501 stream-wise points. The cross-stream width of the grid was $328 \mathrm{ft}$ and the centerline stream-wise distance was approximately $2.5 \mathrm{mi}$. Distances between nodes varied with the curvilinear grid, but the stream-wise increment along the centerline was $8.69 \mathrm{ft}$ and the cross-stream increment was $5.48 \mathrm{ft}$. 
Table 1. Selected model parameters for SToRM model simulations.

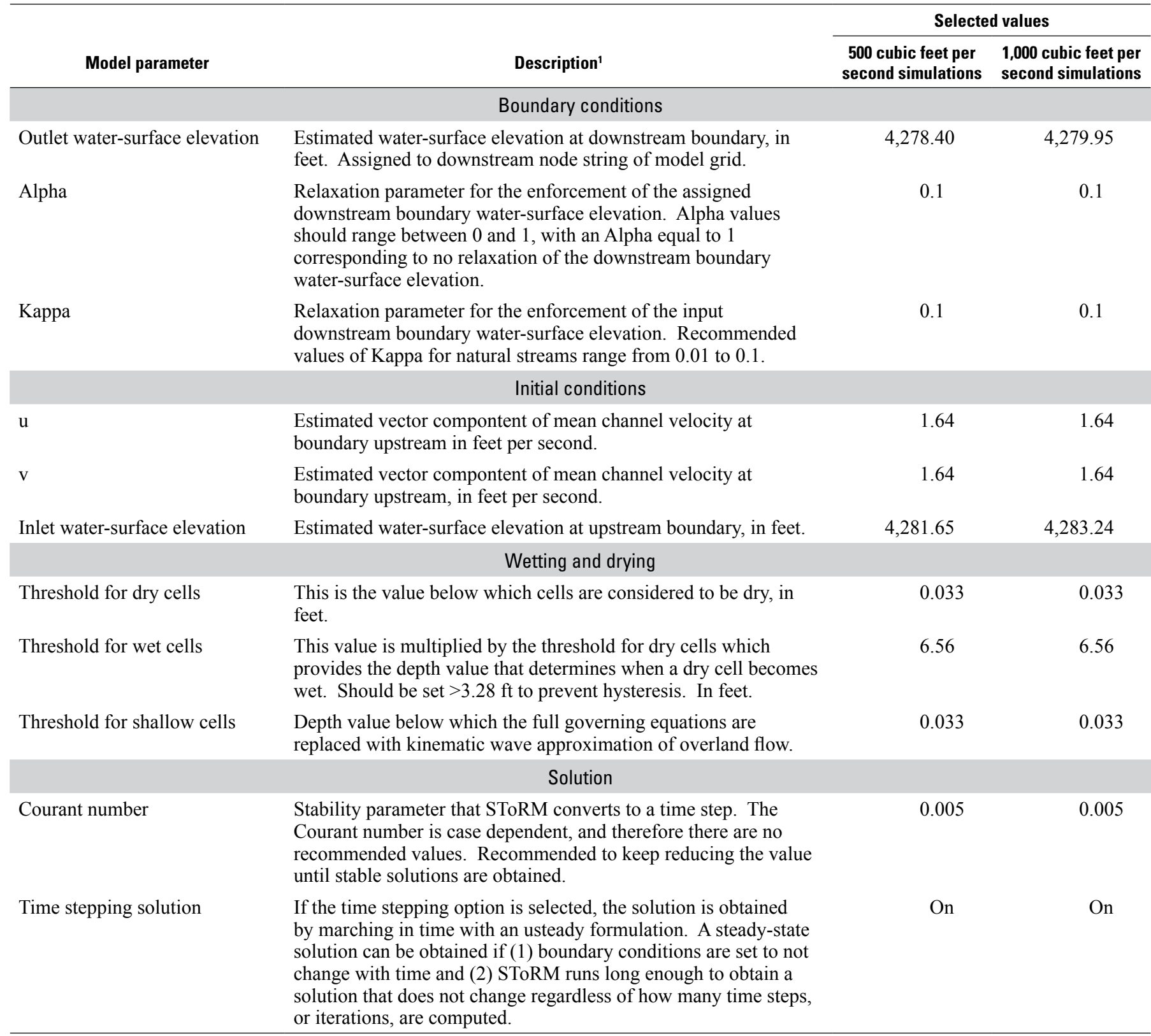

${ }^{1}$ From F.J.M. Simões, U.S. Geological Survey (written commun., April 2008).

\section{Model Input Parameters and Boundary Conditions}

Two streamflows were selected for simulation using the FaSTMECH model of the study reach. The streamflows were selected to meet the USEPA's mitigation design needs throughout the reach. Salt Lake County uses a streamflow of $1,040 \mathrm{ft}^{3} / \mathrm{s}$ as a representative peak-flow design discharge for the Jordan River (Steve Jensen, Salt Lake County Engineering, oral commun., September 2008); therefore, this streamflow was selected for simulation using the constructed
FaSTMECH model. The period of record maximum streamflow $\left(2,790 \mathrm{ft}^{3} / \mathrm{s}\right)$ for Salt Lake County streamflowgaging station 150, Jordan River at 9000 South, was chosen to provide an understanding of shearing forces related to extreme streamflow in the study reach.

Channel roughness in FaSTMECH is represented by a dimensionless drag coefficient. Similar to the Manning's roughness coefficient, the frictional effect of the drag coefficient on streamflow is a function of the flow depth. Tools available in MD_SWMS provide a means for computing drag coefficients for all nodes in the model domain from measured 


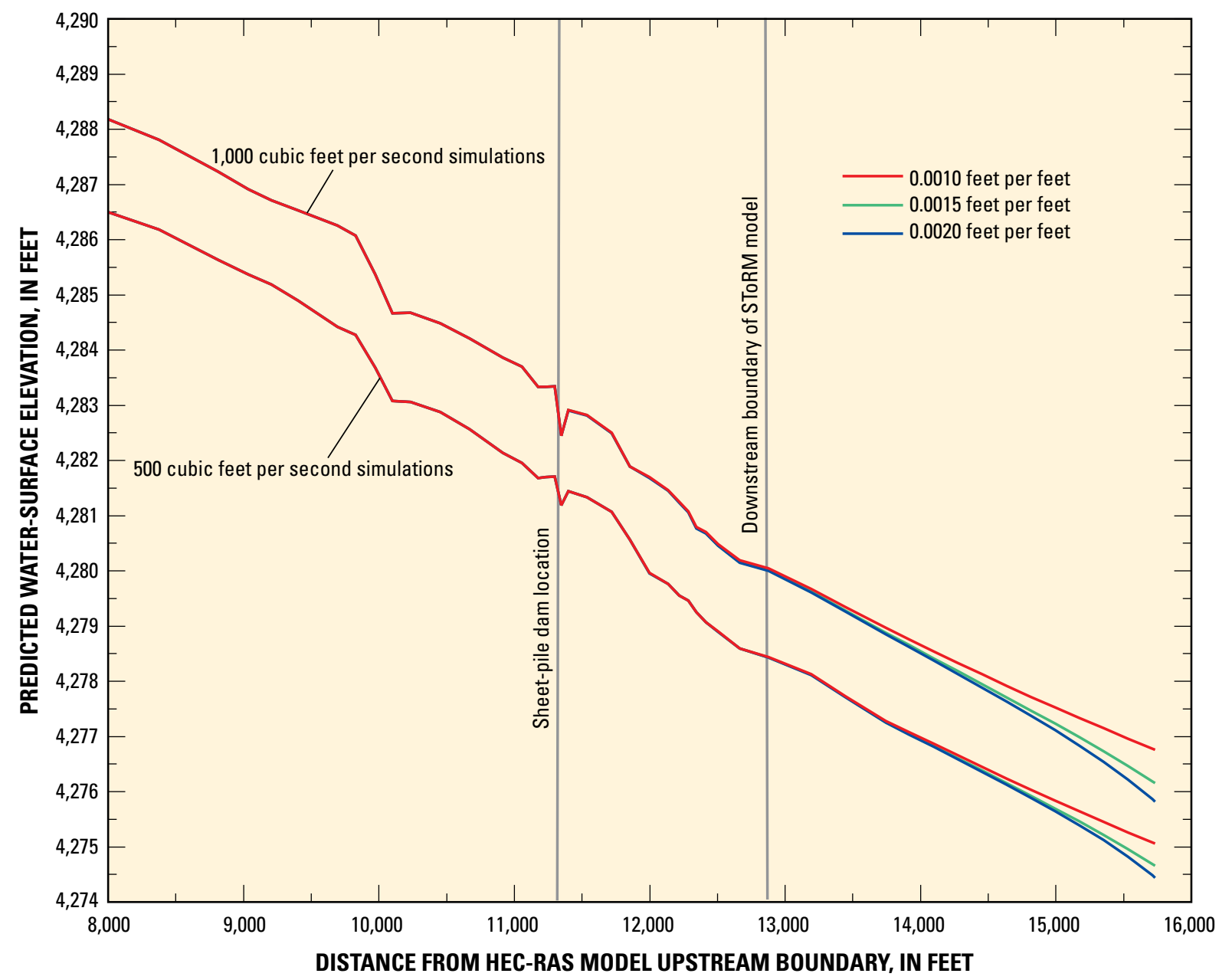

Figure 8. Water-surface profiles for streamflows of 500 and 1,000 cubic feet per second associated with channel slopes of $0.0010,0.0015$, and 0.0020 foot per foot.

bed-material sizes and estimated flow depths. The median bed-material grain size, or D50, of $5.5 \mathrm{~mm}$ for the southern portion of the study reach (Huffman and Carpenter, Inc., written commun., 2001) was used in the computation of drag coefficients throughout the reach for each of the simulated streamflows.

The downstream boundary water-surface elevation and either an initial estimate of the upstream water surface or an estimate of the regional slope are required input conditions of the FaSTMECH model. The same HEC-RAS model that was used for the SToRM models discussed in the SToRM Model section of this report was adjusted to represent the geometry of the newly constructed replacement structure. The HEC-RAS model was calibrated to the measured watersurface elevations associated with an observed streamflow of $1,100 \mathrm{ft}^{3} / \mathrm{s}$. The calibration consisted of adjusting Manning's $n$ values for the cross sections of the HEC-RAS model until observed water-surface elevations agreed with predicted water-surface elevations. Manning's $n$ values for the main channel generally ranged from 0.030 to 0.038 . This adjusted and calibrated model then was used to determine the boundary conditions for the study reach FaSTMECH model. The water-surface elevation at the most downstream cross section was set at normal depth (Federal Emergency Management Agency, 2003) in HEC-RAS using the slope of $0.0014 \mathrm{ft} / \mathrm{ft}$ of the energy grade line downstream from the Union Pacific Railroad Bridge as computed from the calibration streamflow simulation of $1,100 \mathrm{ft}^{3} / \mathrm{s}$. The streamflows of interest then were set at the upstream boundary. From these steady-state simulations, water-surface elevations for each of the 73 cross sections of the study reach were obtained by using the energy equation method used in HEC-RAS. Manning's $n$ values determined during the calibration procedure were used for both streamflow simulations. Solved water-surface elevations for the cross section located at the downstream boundary of the FaSTMECH model are shown in table 2.

The FaSTMECH model requires a number of model parameters to be defined in order to obtain a valid and stable solution. These values are dependent on the hydraulic characteristics of the reach represented by the model domain 
and optimum values are resolved generally through a trial and error process. Initial model parameters were determined from suggested guidelines for the hydraulic characteristics of the observed streamflow of $1,100 \mathrm{ft}^{3} / \mathrm{s}$. Final parameters were resolved when a valid and stable simulation of the observed streamflow was achieved. The same model parameters, other than the upstream streamflow and downstream water-surface elevation, were used when simulating the two streamflows of interest, $1,040 \mathrm{ft}^{3} / \mathrm{s}$ and $2,790 \mathrm{ft}^{3} / \mathrm{s}$. Selected model parameters for the FaSTMECH model simulations are contained in table 2.

\section{Model Calibration and Verification}

Water-surface elevations throughout the study reach and water velocities at selected cross sections were acquired at a streamflow of $1,100 \mathrm{ft}^{3} / \mathrm{s}$ on May 6, 2009. These elevations and velocities represent the channel configuration associated with the new structure and therefore were used to calibrate and verify the FaSTMECH model. Using an RTK-GPS, water-surface elevations were measured at 66 locations throughout the study reach. An acoustic Doppler current profiler (ADCP) interfaced with a differential global positioning system (DGPS) was deployed from a tethered boat at eight cross sections in the study reach (fig. 9). The ADCP measures velocity along a transect, or cross section, and vertically through most of the water column. In order to make comparisons with the modeled velocities of the FaSTMECH model, which represent vertically averaged velocities, the measured three-dimensional velocities obtained with the ADCP were vertically averaged.
Before simulating the streamflows of interest, the observed streamflow of $1,100 \mathrm{ft}^{3} / \mathrm{s}$ was simulated with the FaSTMECH model and a valid and stable solution was achieved. The downstream boundary water-surface elevation was set to the measured water-surface elevation of $4,279.29 \mathrm{ft}$ for the 1,100 $\mathrm{ft}^{3} / \mathrm{s}$ streamflow. As described previously, model parameters were adjusted until a satisfactory solution was obtained, and are contained in table 2. Channel roughness, represented by dimensionless drag coefficients, was computed based on the bed material D50 and therefore was not adjusted during calibration. The relation between predicted and observed water-surface elevations (fig. 10) suggests that the computed drag coefficients for the study reach, described previously, are adequately representing the channel roughness. The standard deviation of the residuals, which are computed as the predicted water-surface elevation minus the observed watersurface elevation, is $0.24 \mathrm{ft}$ and the average residual is $-0.06 \mathrm{ft}$. The observed water-surface elevations generally are greater than the predicted water-surface elevations in the upper and lower parts of the study reach, and predicted water-surface elevations are greater upstream from the 7800 South Bridge. General agreement between observed and predicted watersurface elevations occurs upstream and downstream from the constructed replacement structure and in various locations in the upper portions of the study reach.

The relation between observed and predicted vertically averaged velocities for the observed streamflow of $1,100 \mathrm{ft}^{3} / \mathrm{s}$, plotted by cross-stream distance, at eight cross sections is shown in figure 11 . The acquired velocity data allow for an examination of how well the model is simulating the spatial distribution of velocity throughout the selected cross sections

Table 2. Select model parameters for FaSTMECH model simulations.

\begin{tabular}{|c|c|c|c|c|}
\hline \multirow[b]{2}{*}{ Model parameter } & \multirow[b]{2}{*}{ Description $^{1}$} & \multicolumn{3}{|c|}{ Selected values } \\
\hline & & $\begin{array}{l}1,040 \text { cubic feet } \\
\text { per second } \\
\text { simulation }\end{array}$ & $\begin{array}{l}{ }^{2} 1,100 \text { cubic } \\
\text { feet per second } \\
\text { simulation }\end{array}$ & $\begin{array}{l}2,790 \text { cubic feet } \\
\text { per second } \\
\text { simulation }\end{array}$ \\
\hline \multicolumn{5}{|c|}{ Boundary conditions } \\
\hline $\begin{array}{l}\text { Downstream water-surface } \\
\text { elevation }\end{array}$ & $\begin{array}{l}\text { Estimated water-surface elevation at downstream } \\
\text { boundary, in feet. }\end{array}$ & $4,279.09$ & $4,279.29$ & $4,283.26$ \\
\hline $\begin{array}{l}\text { Lateral eddy viscosity } \\
\text { coefficient }\end{array}$ & $\begin{array}{l}\text { A recommended range for the lateral eddy viscosity is } \\
\text { between }(0.01 * \text { average depth } * \text { average velocity }) \text { and } \\
(0.11 * \text { average depth } * \text { average velocity }), \text { in feet squared } \\
\text { per second. }\end{array}$ & 0.32 & 0.32 & 0.32 \\
\hline \multicolumn{5}{|c|}{ Initial conditions } \\
\hline Regional slope & Estimated slope of the study reach, in feet per feet. & 0.0021 & 0.0021 & 0.0021 \\
\hline U-relax & Relaxation coefficient for the velocity. & 0.6 & 0.6 & 0.6 \\
\hline A-relax & A global relaxation coefficient. & 0.6 & 0.6 & 0.6 \\
\hline
\end{tabular}

${ }^{1}$ From R.R. McDonald, U.S. Geological Survey (written commun., April 2008).

${ }^{2}$ Observed streamflow. 


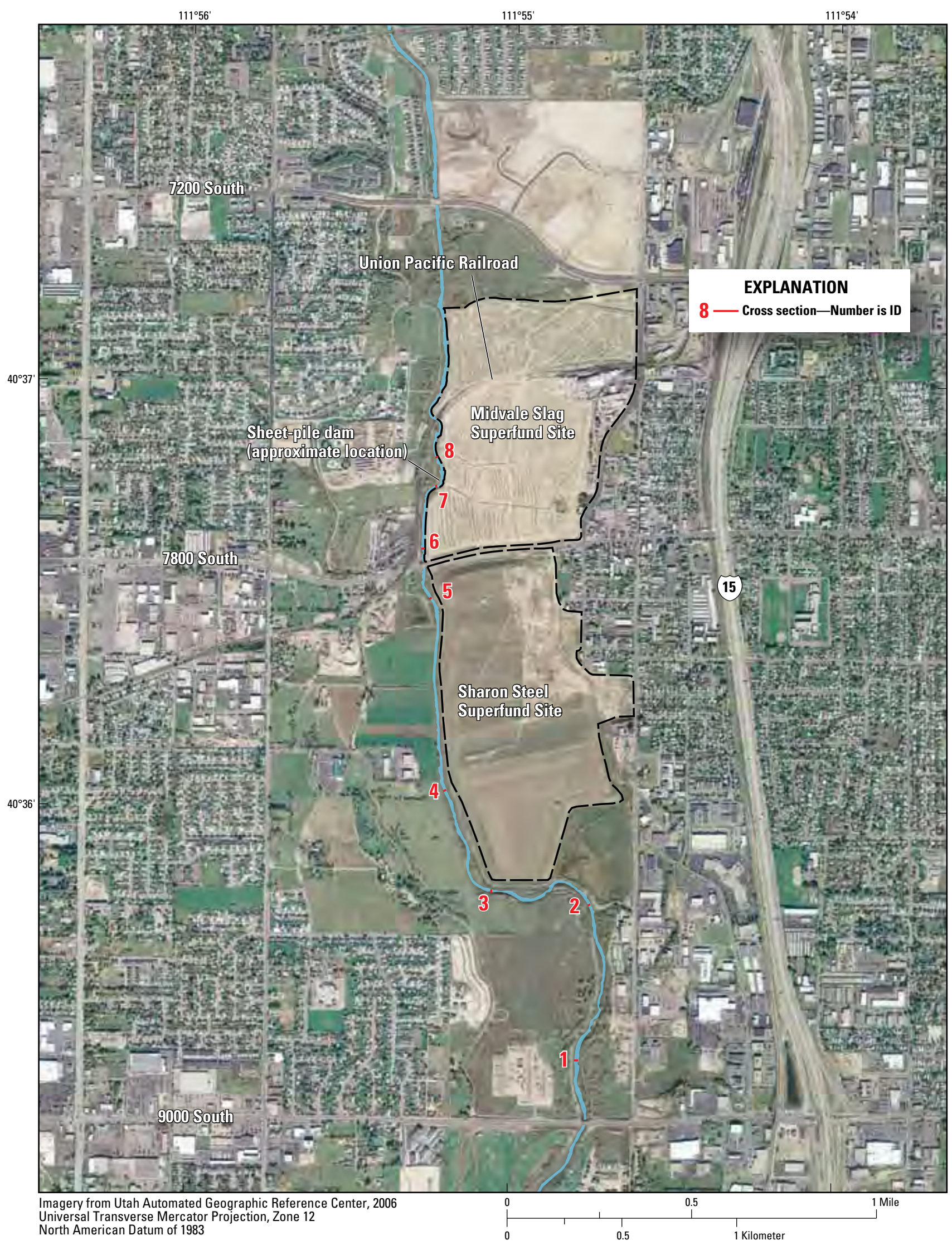

Figure 9. Location of cross section velocity measurements, Midvale and West Jordan, Utah. 


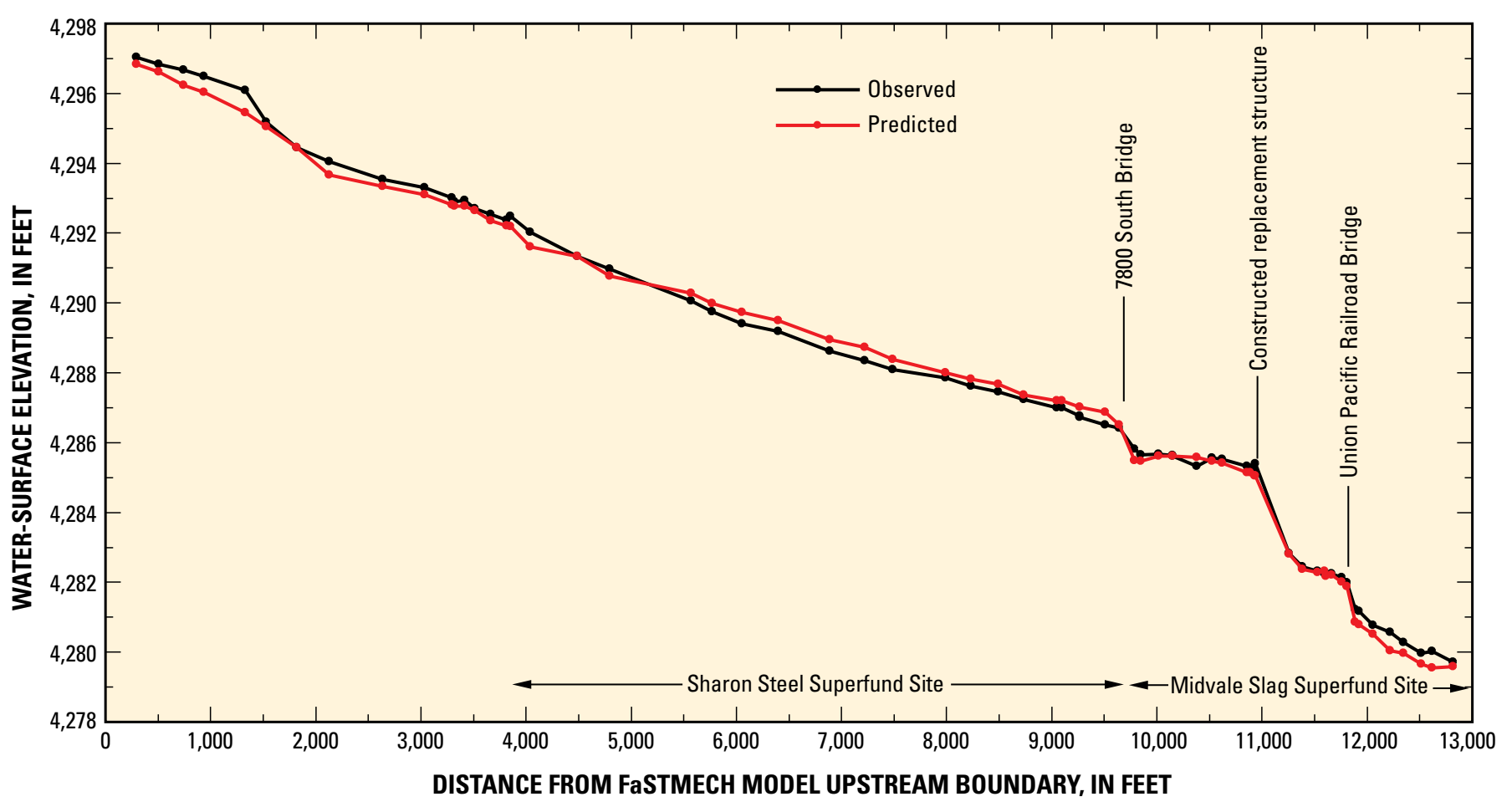

Figure 10. Observed and predicted water-surface elevations for a streamflow of 1,100 cubic feet per second.

(Kenney, 2006). In general, model predicted velocities are contained within the range of observed velocities for cross sections $1-4$ and 8 . At cross sections 5 through 7, the spatial distribution of predicted and observed velocities across the stream differ. The horizontal distribution of predicted velocities at cross section 5 is constant, ranging between about 3 and $4 \mathrm{ft} / \mathrm{s}$, while the observed velocities range from near 0 to greater than $7 \mathrm{ft} / \mathrm{s}$. At cross section 6 , predicted velocities indicate a horizontal distribution with small velocities on the left and larger velocities on the right. The observed horizontal distribution shows the greatest velocities to be in the center of the channel and decreasing towards the banks. The largest observed velocities at cross section 7 are shown to occur near the right bank, while the predicted horizontal velocity distribution shows the greatest to be in the center of the channel. It is difficult to determine the causes of these differences between observed and predicted velocities at cross sections 5 through 7 . The differences are most likely because of poor topographic representation of the cross sections in the model, or possibly local channel roughness differences that were not accounted for, such as from drag associated with vegetation. The bathymetric survey data were collected in February 2008, before construction associated with the sheet-pile dam began. Similarly, construction activities on the east bank of the river from the 7800 South Bridge to the sheet-pile dam occurred after the survey was conducted and before the observed 1,100 ft3 3 s streamflow of May 6, 2009. These construction activities and possible changes in the river topography are the likely cause for the differences between the modeled velocity distribution and the observed velocity distribution at cross sections 5 through 7 . The standard deviation of the residuals, which are computed as the predicted velocity minus the observed velocity, for the eight cross sections is $1.60 \mathrm{ft} / \mathrm{s}$ and the average residual is $-0.18 \mathrm{ft} / \mathrm{s}$. 

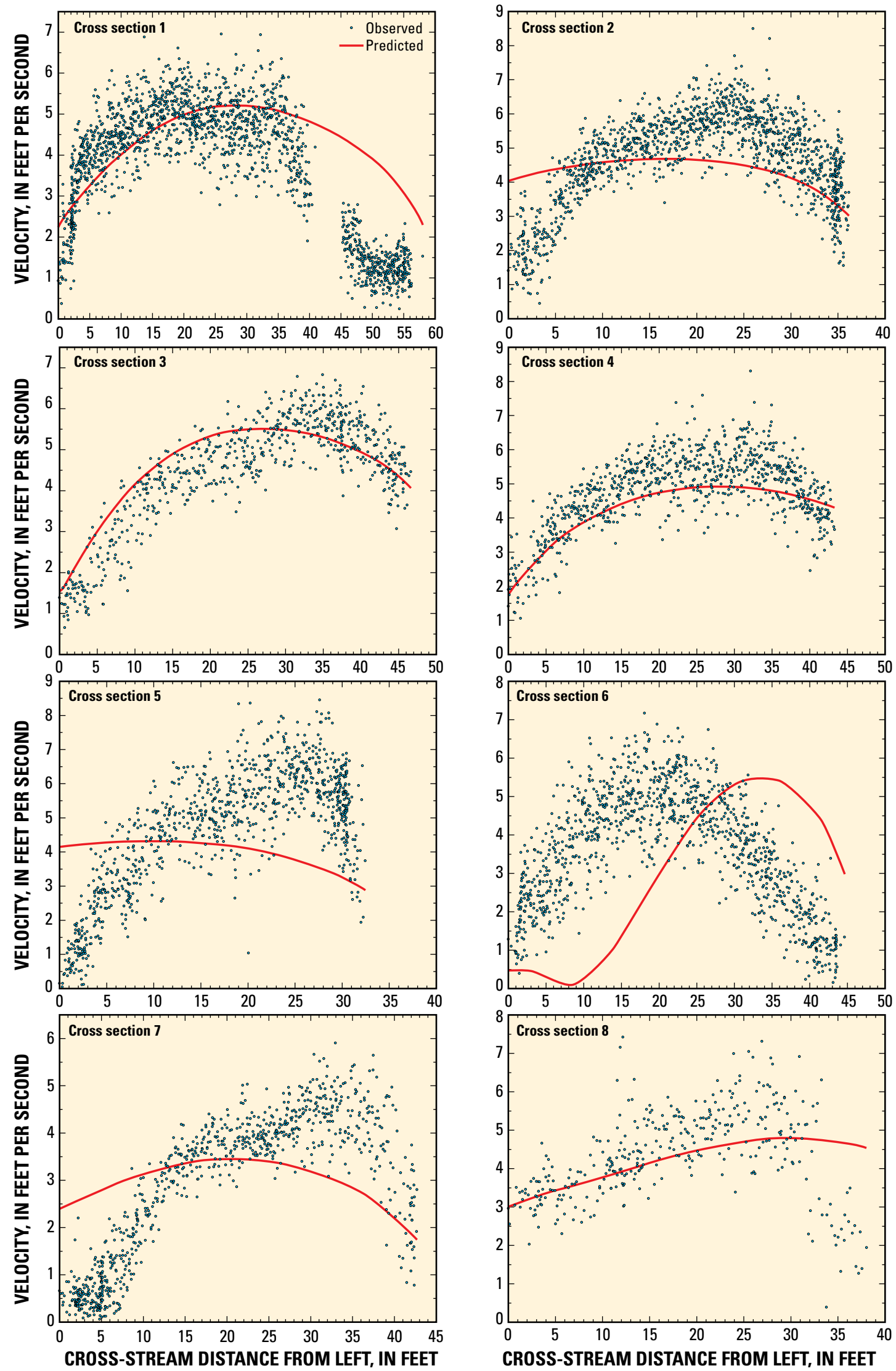

Figure 11. Relation between observed and predicted velocities for a streamflow of 1,100 cubic feet per second at eight cross sections in the Jordan River, Midvale and West Jordan, Utah. 


\section{Results}

Results generated by the SToRM model included watersurface elevations and velocities associated with the topography of the existing sheet-pile dam and the proposed structure. These results provided the USEPA with a quantitative assessment of the hydraulic characteristics of the proposed replacement structure. As part of this assessment, direct comparisons of water-surface elevations and velocities through the sheetpile dam subreach were provided. The FaSTMECH model provided a spatial understanding of the water-surface elevations, velocities, and shear stress for the entire study reach that encompassed the two USEPA Superfund Sites associated with high flow. The results enabled engineers to develop bank armoring and erosional control designs using quantified hydraulic conditions from a verified model.

\section{Comparison of Water-Surface Elevations and Velocities of Existing Sheet-Pile and Proposed Replacement Structure}

The results of the SToRM model enabled a comparison of the hydraulic conditions associated with the topography of the existing sheet-pile dam and the proposed structure. As discussed above, the same unstructured model grid was used for the two simulated streamflows of each structure topography, including the existing structure. Because of this, differences in water-surface elevations and velocities at each model node between the sheet-pile dam simulations and proposed structure topography simulations were computed. These computed differences were then plotted and contoured on an aerial photograph to illustrate the locations where velocity or water-surface elevation were predicted to be different from those associated with the existing sheet-pile dam.

\section{Comparison of Water-Surface Elevations}

Maps were created showing differences in water-surface elevations between three of the five replacement structure configurations (as designed, increased topography of $1.0 \mathrm{ft}$, and increased topography of $2.0 \mathrm{ft}$ ) and the existing sheet-pile dam for simulated streamflows of $500 \mathrm{ft}^{3} / \mathrm{s}$ (figs. 12-14) and $1,000 \mathrm{ft}^{3} / \mathrm{s}$ (figs. 15-17). Water-surface elevation differences in the vicinity of the existing sheet-pile dam (shown on the maps) appear somewhat varied. This is because of the differences in topography between the sheet-pile dam, and the ramp form of the proposed structure (see figs. $6 B$ and 7) and therefore is not discussed in this assessment of the proposed replacement structures. For the two simulated streamflows, the watersurface elevations of the as designed configuration of the proposed structure were most similar to those of the existing sheet-pile dam. In general, water-surface elevation differences increase in magnitude and expand upstream with the increase in the elevations of the proposed structure. The largest magnitude of water-surface elevation differences is associated with the $500 \mathrm{ft}^{3} / \mathrm{s}$ simulation for the increased topography of $2.0 \mathrm{ft}$ configuration. For this structure configuration the model predicts water-surface elevation increases of between 0.7 and $1.0 \mathrm{ft}$ throughout the main channel for approximately $250 \mathrm{ft}$ immediately upstream from the structure. The 1,000 $\mathrm{ft}^{3} / \mathrm{s}$ simulation for this configuration predicts water-surface elevation increases of slightly less magnitude, between 0.4 and $0.7 \mathrm{ft}$, in this region; however, the upstream range of differences greater than $0.1 \mathrm{ft}$ is about equal for both streamflows. The two other configurations of the proposed structure (increased topography of $0.5 \mathrm{ft}$ and increased topography of $1.5 \mathrm{ft}$ ) generally followed the predicted trend of differences shown by the results of the as designed, increased topography of $1.0 \mathrm{ft}$ and increased topography of $2.0 \mathrm{ft}$, configurations and therefore are not contained in this report.

\section{Comparison of Velocities}

Maps were created showing differences in velocities between three of the five replacement structure configurations (as designed, as designed plus $1.0 \mathrm{ft}$, and as designed plus 2.0 $\mathrm{ft}$ ) and the existing sheet-pile dam for simulated streamflows of $500 \mathrm{ft}^{3} / \mathrm{s}$ (figs. 18-20) and 1,000 $\mathrm{ft}^{3} / \mathrm{s}$ (figs. 21-23).

Velocities in the vicinity of the existing sheet-pile dam are shown to increase with the proposed structure configurations, which are associated with the topographic differences between the sharp-crested sheet-pile dam and the ramp design of the proposed structure. In general, predicted main-channel velocities upstream from the structure for the as designed and as designed plus $1.0 \mathrm{ft}$ structure topographies are within -0.5 and $1.5 \mathrm{ft} / \mathrm{s}$ of those associated with the existing sheet-pile dam for both simulated streamflows. Upstream velocities predicted for the proposed structure configuration of an increased $2.0 \mathrm{ft}$ indicate decreases in velocity of between -0.5 and $-1.5 \mathrm{ft} / \mathrm{s}$ for the $500 \mathrm{ft}^{3} / \mathrm{s}$ simulation and between -0.5 and $-1.0 \mathrm{ft} / \mathrm{s}$ for the $1,000 \mathrm{ft}^{3} / \mathrm{s}$ simulation when compared with the predictions for the existing sheet-pile dam. Some of the difference maps show small localized areas of large velocity differences; these likely are because of locations in the existing sheet-pile dam model that were predicted to be dry yet became submerged in one or more of the proposed topography models. Of importance to this analysis are the continuous regions of the channel showing differences. Similar to the examination of water-surface elevations, the two other configurations of the proposed structure (increased topography of $0.5 \mathrm{ft}$ and increased topography of $1.5 \mathrm{ft}$ ) generally followed the predicted trend of differences shown by the results of the as designed, increased topography of $1.0 \mathrm{ft}$, and increased topography of $2.0 \mathrm{ft}$ configurations and therefore are not contained in this report. 


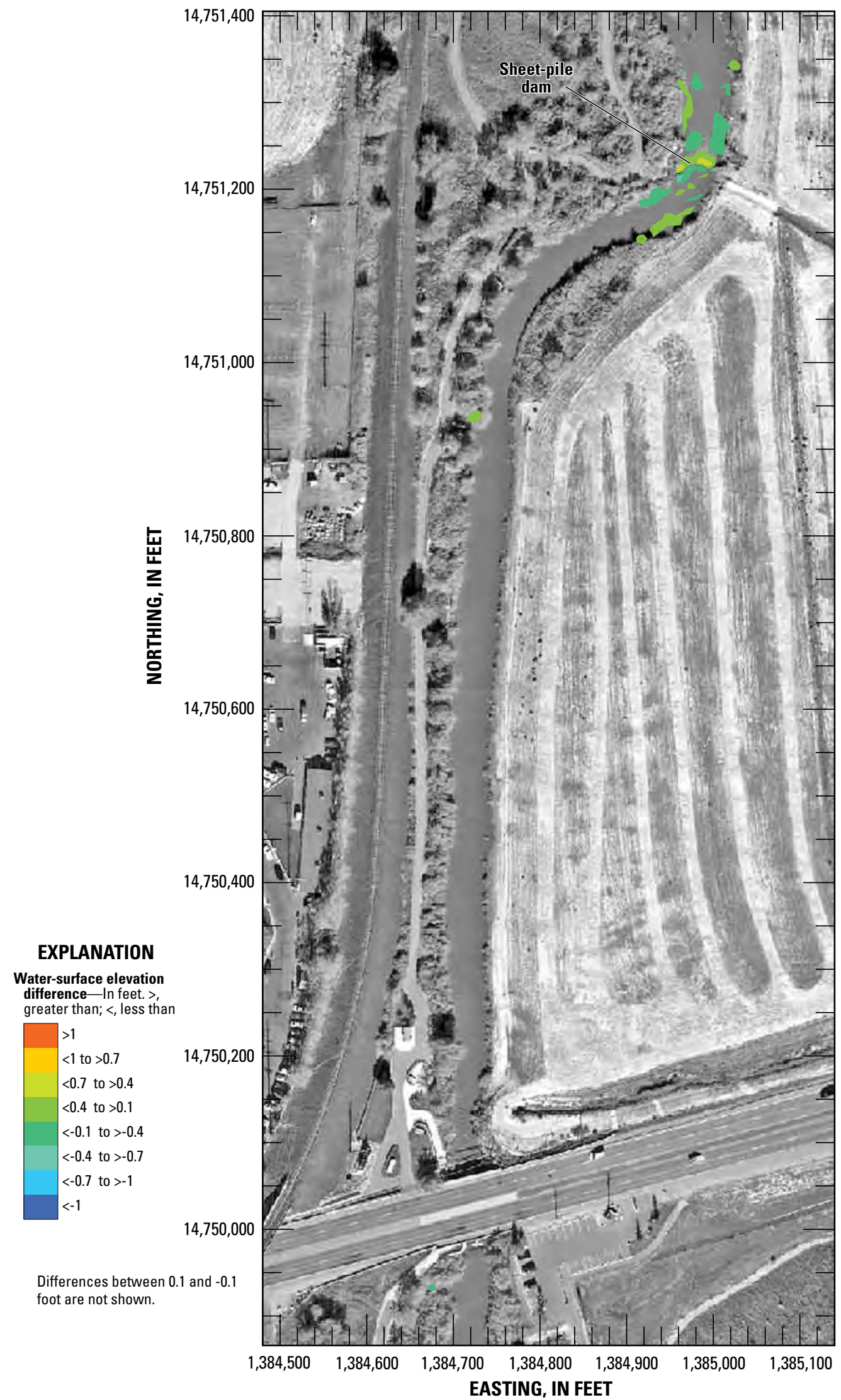

Figure 12. Predicted water-surface elevations for the proposed replacement structure as designed minus predicted water-surface elevations for the existing sheet-pile dam for a streamflow of 500 cubic feet per second. 


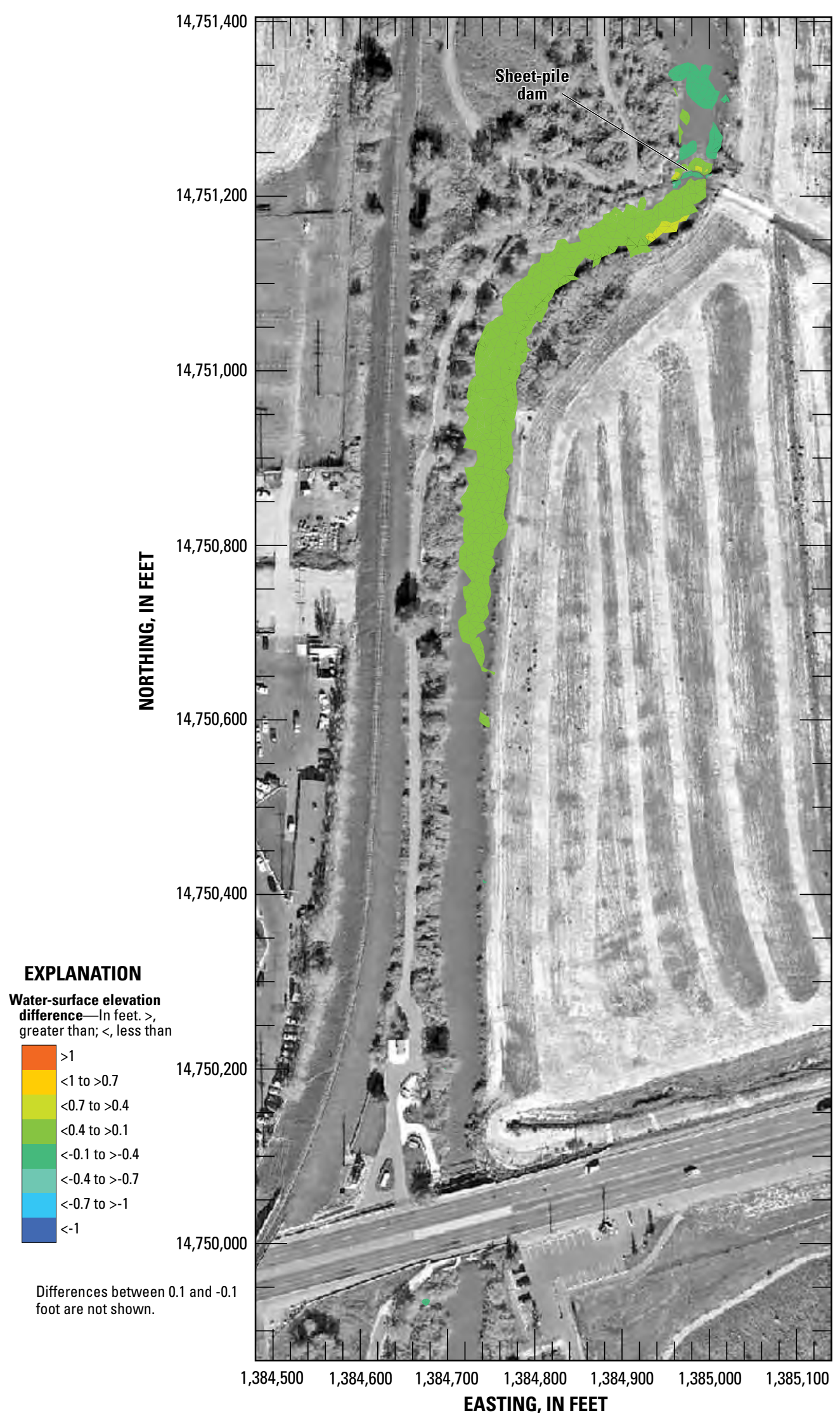

Figure 13. Predicted water-surface elevations for the proposed replacement structure with an increased topography of 1.0 foot minus predicted water-surface elevations for the existing sheet-pile dam for a streamflow of 500 cubic feet per second. 


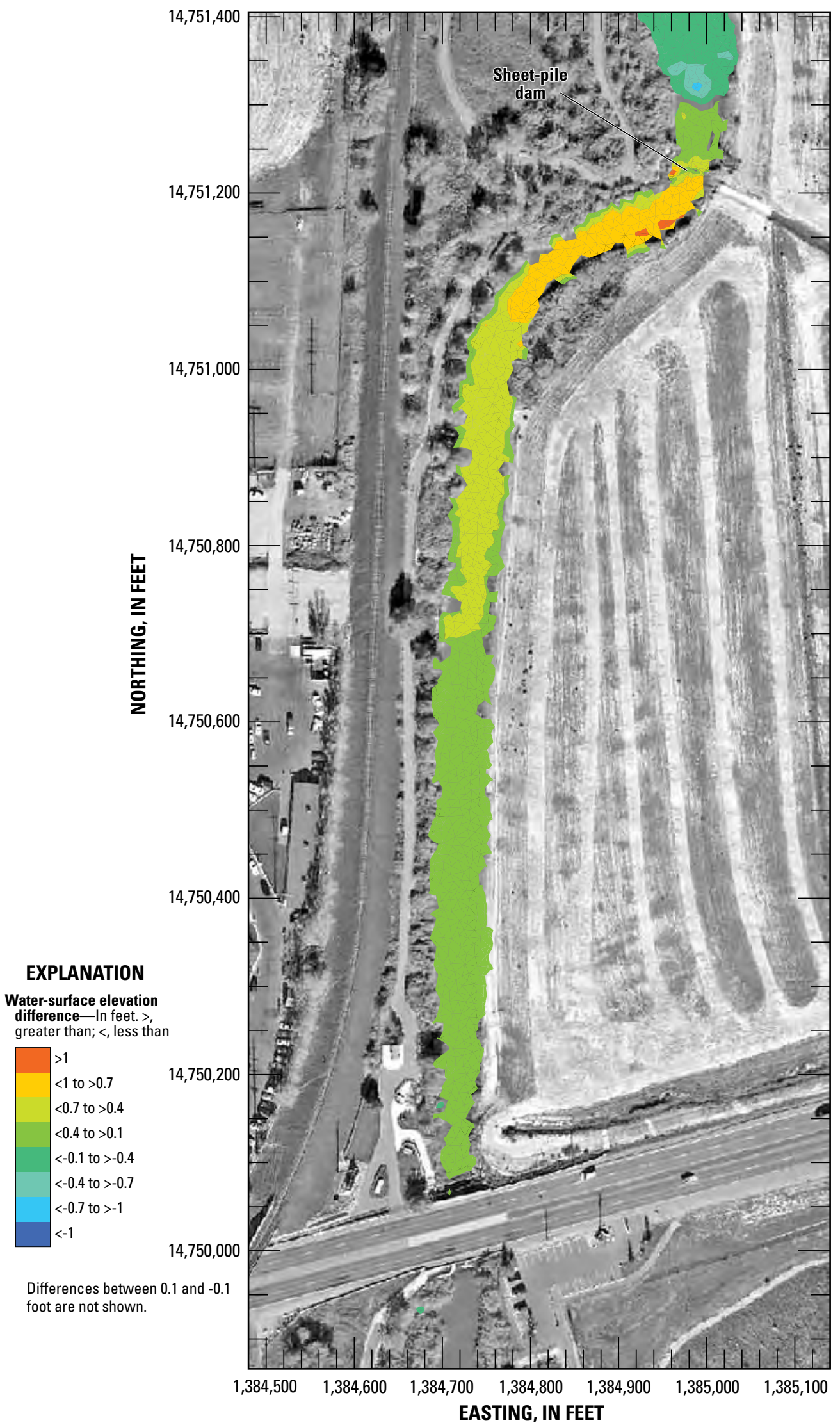

Figure 14. Predicted water-surface elevations for the proposed replacement structure with an increased topography of 2.0 feet minus predicted water-surface elevations for the existing sheet-pile dam for a streamflow of 500 cubic feet per second. 


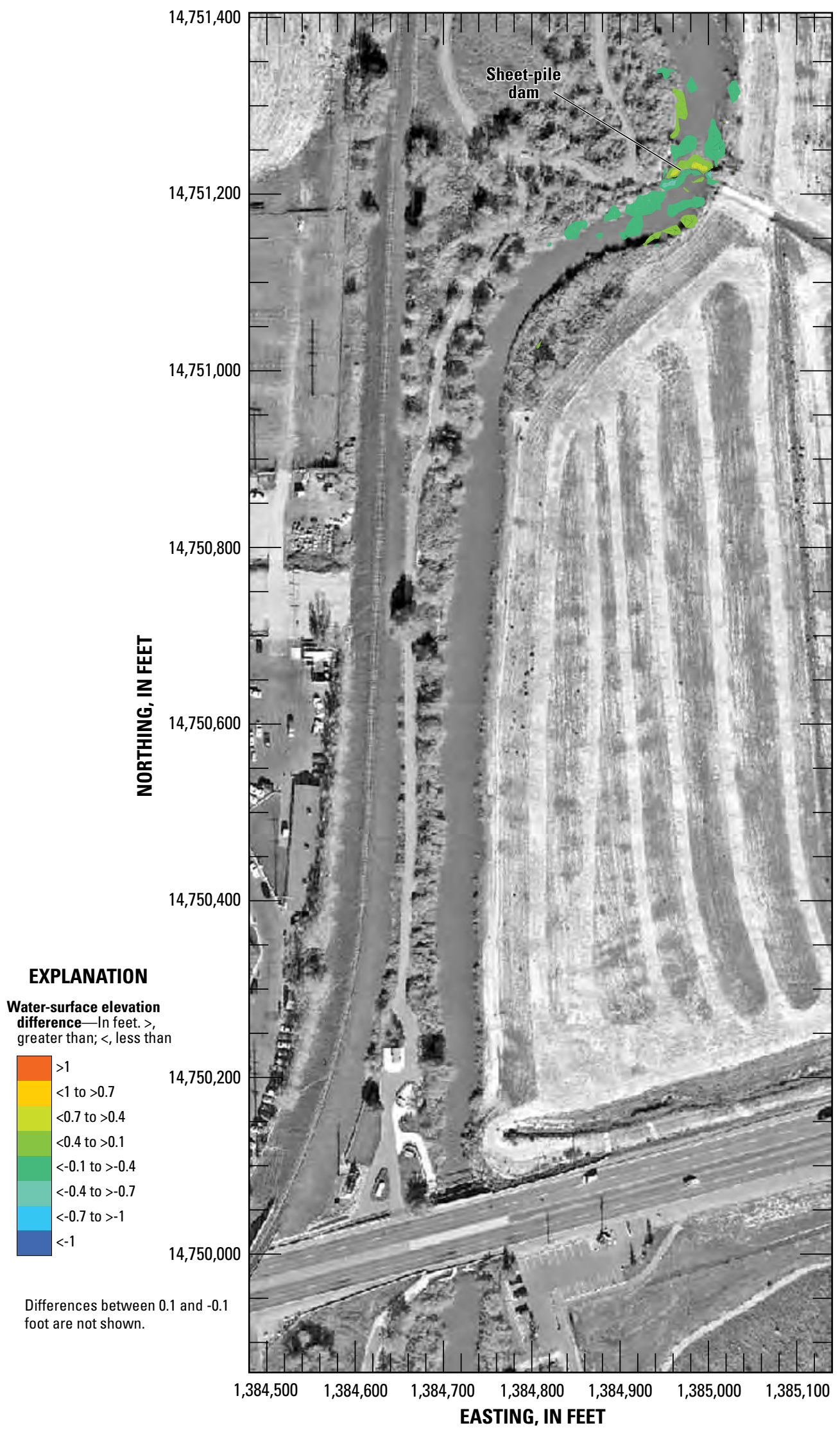

Figure 15. Predicted water-surface elevations for the proposed replacement structure as designed minus predicted water-surface elevations for the existing sheet-pile dam for a streamflow of 1,000 cubic feet per second. 


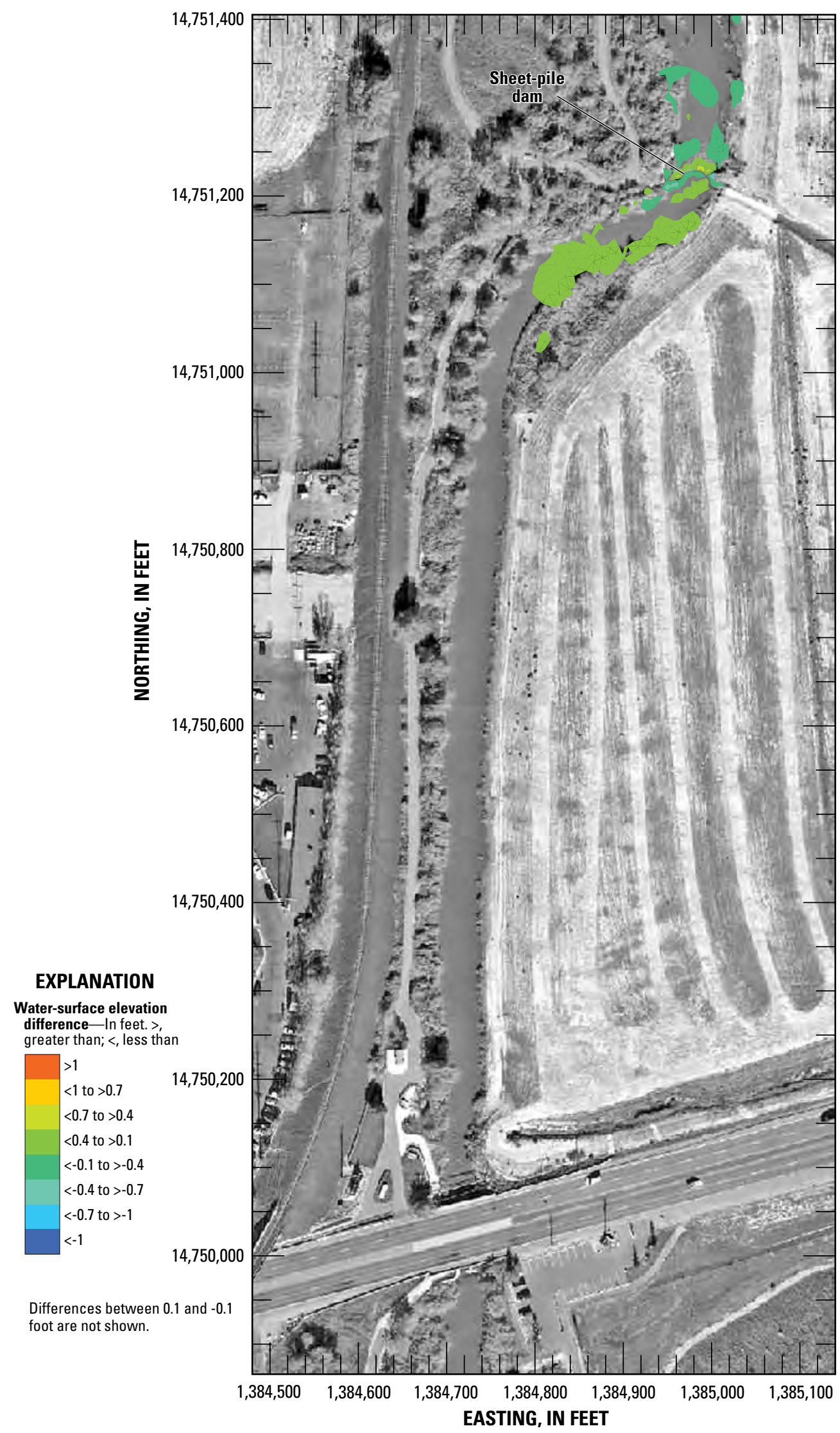

Figure 16. Predicted water-surface elevations for the proposed replacement structure with an increased topography of 1.0 foot minus predicted water-surface elevations for the existing sheet-pile dam for a streamflow of 1,000 cubic feet per second. 


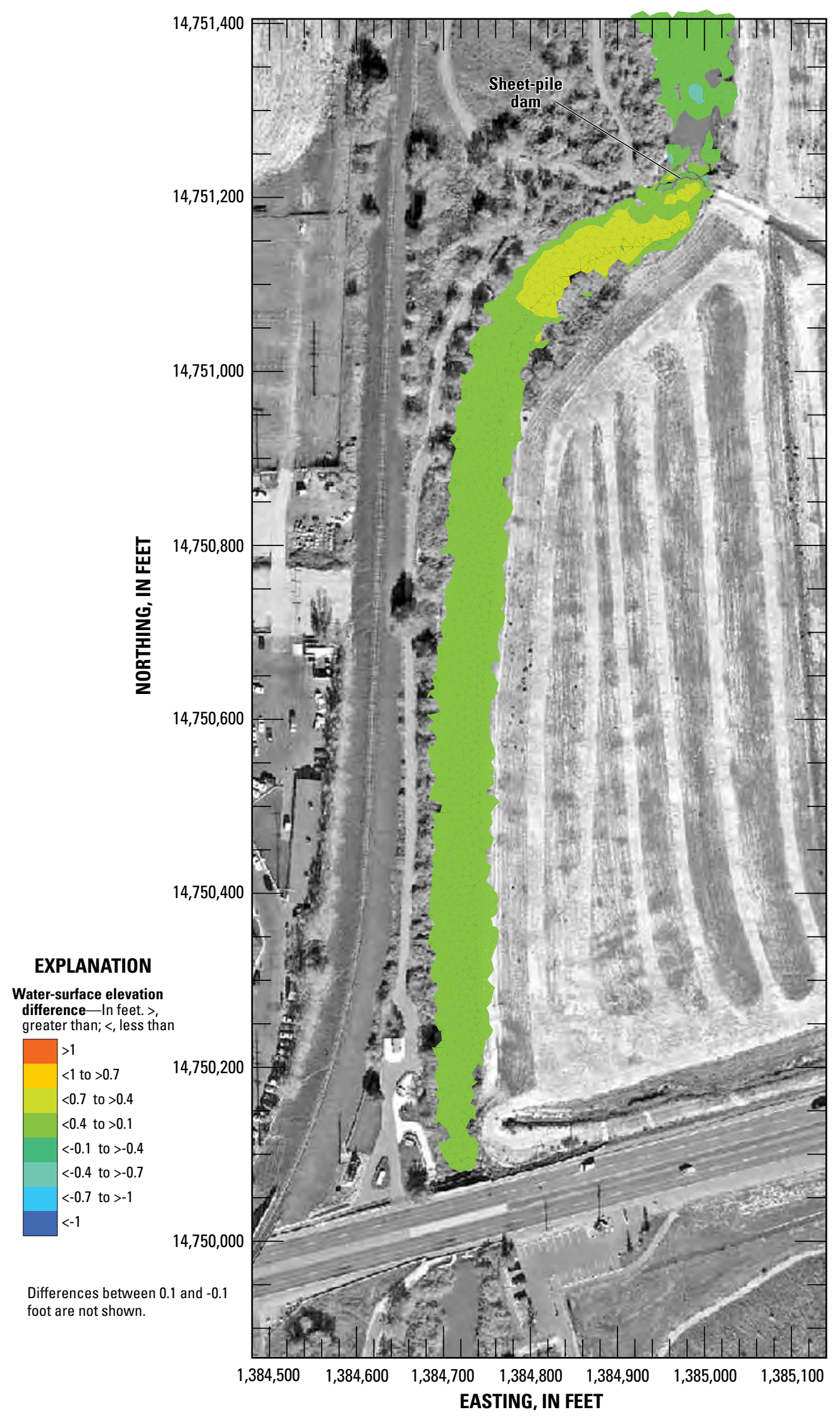

Figure 17. Predicted water-surface elevations for the proposed replacement structure with an increased topography of 2.0 feet minus predicted water-surface elevations for the existing sheet-pile dam for a streamflow of 1,000 cubic feet per second. 


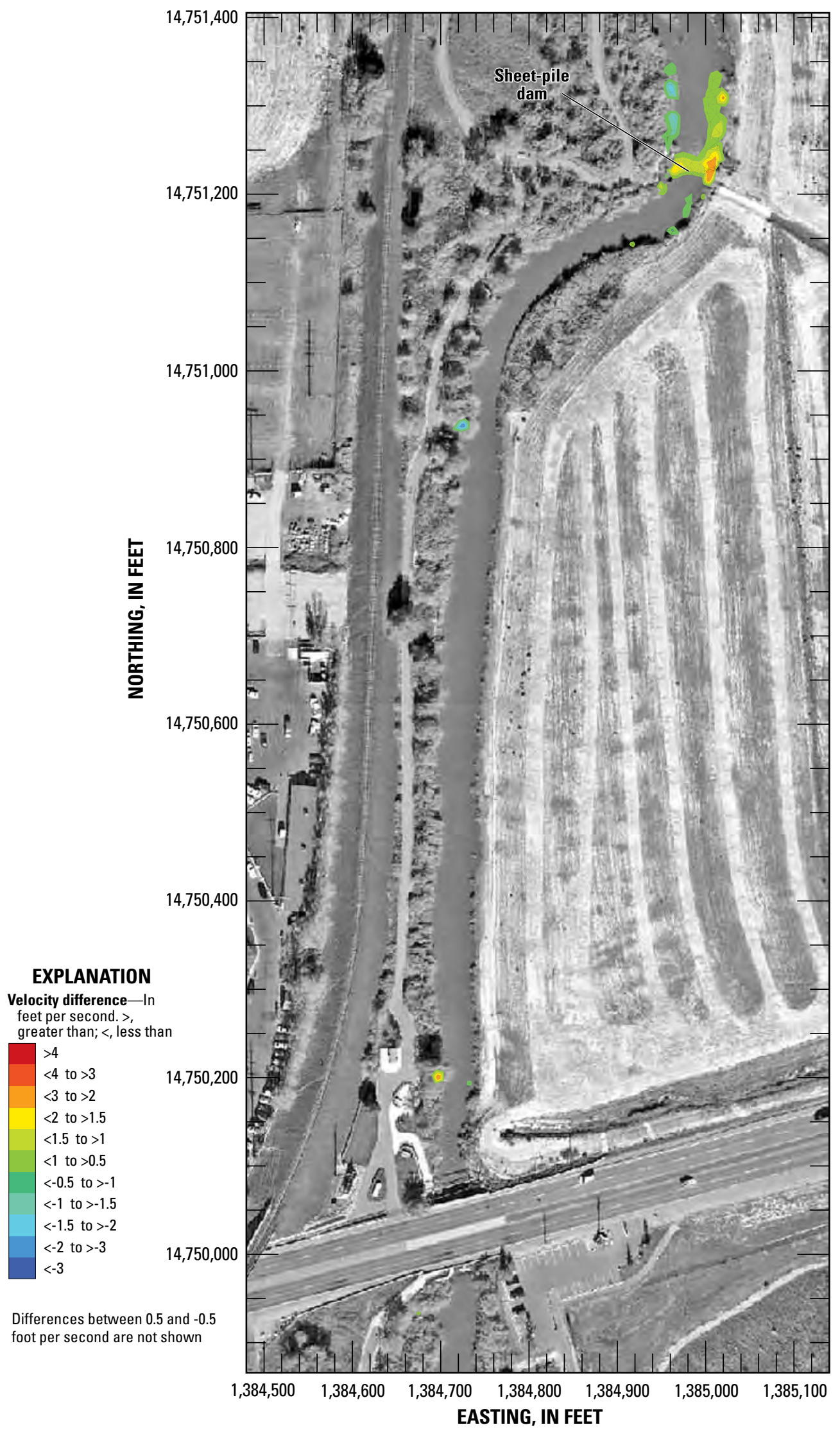

Figure 18. Predicted water velocities for the proposed replacement structure as designed minus predicted water velocities for the existing sheet-pile dam for a streamflow of 500 cubic feet per second. 


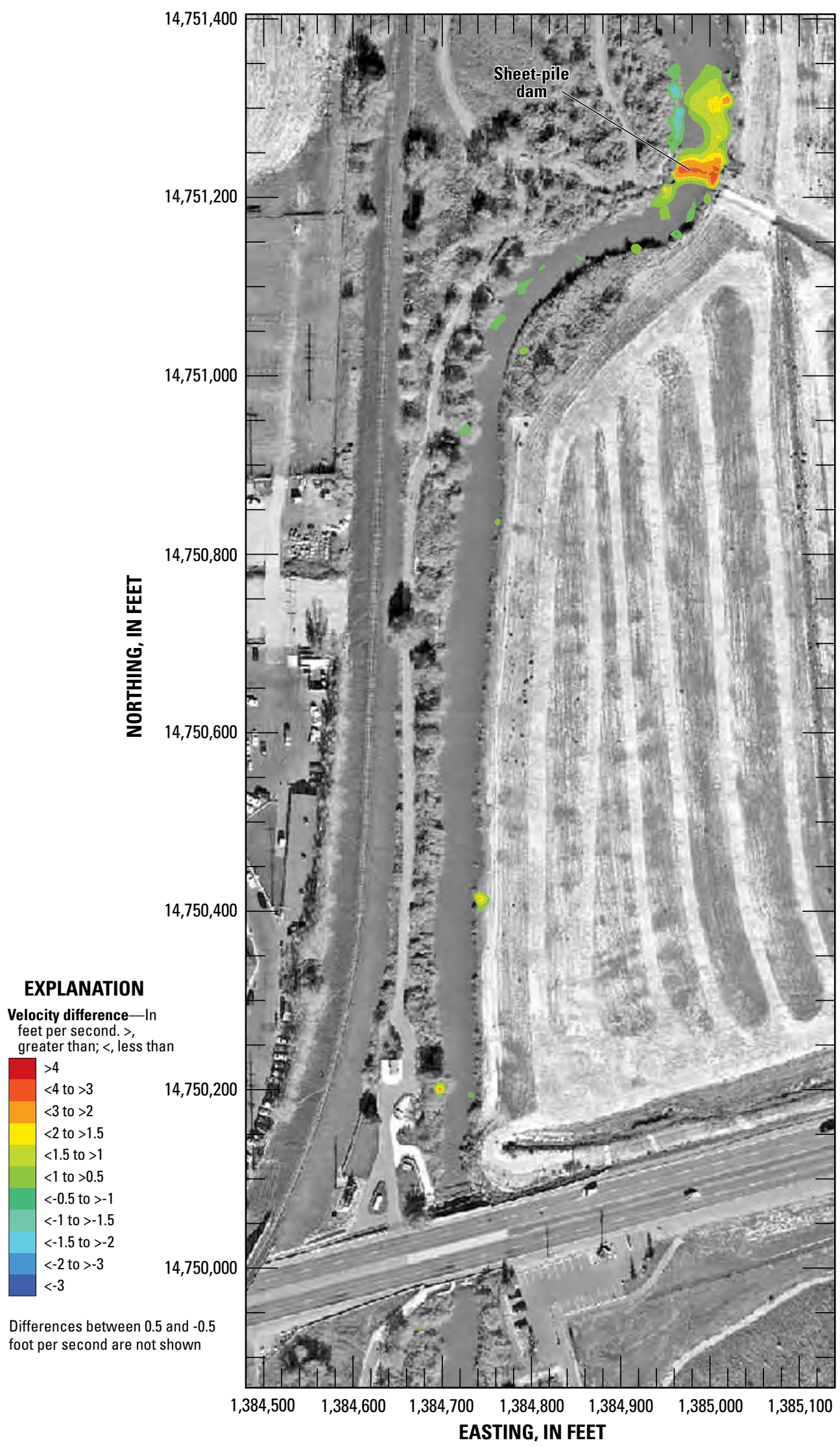

Figure 19. Predicted water velocities for the proposed replacement structure with an increased topography of 1.0 foot minus predicted water velocities for the existing sheet-pile dam for a streamflow of 500 cubic feet per second. 


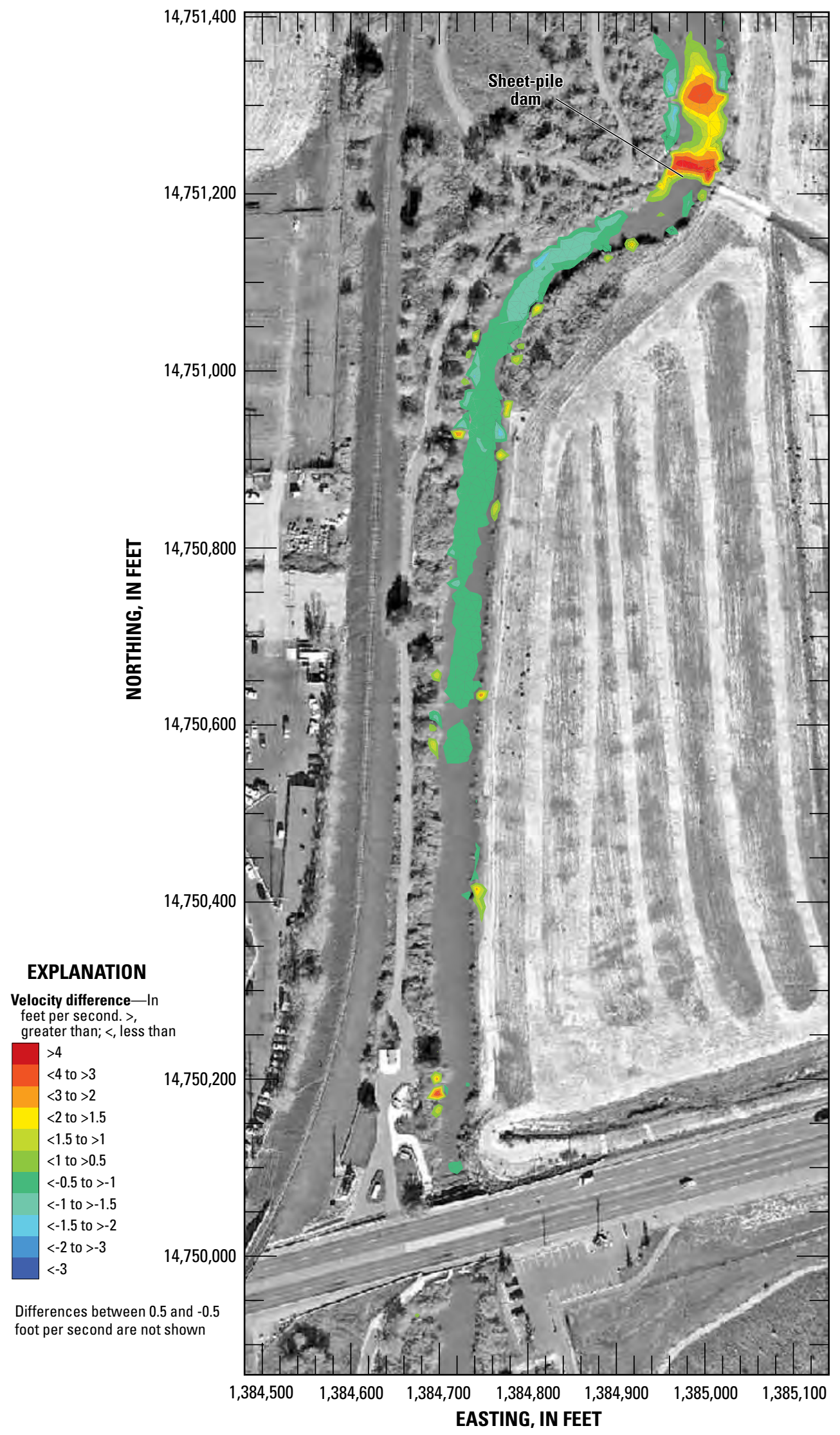

Figure 20. Predicted water velocities for the proposed replacement structure with an increased topography of 2.0 feet minus predicted water velocities for the existing sheet-pile dam for a streamflow of 500 cubic feet per second. 


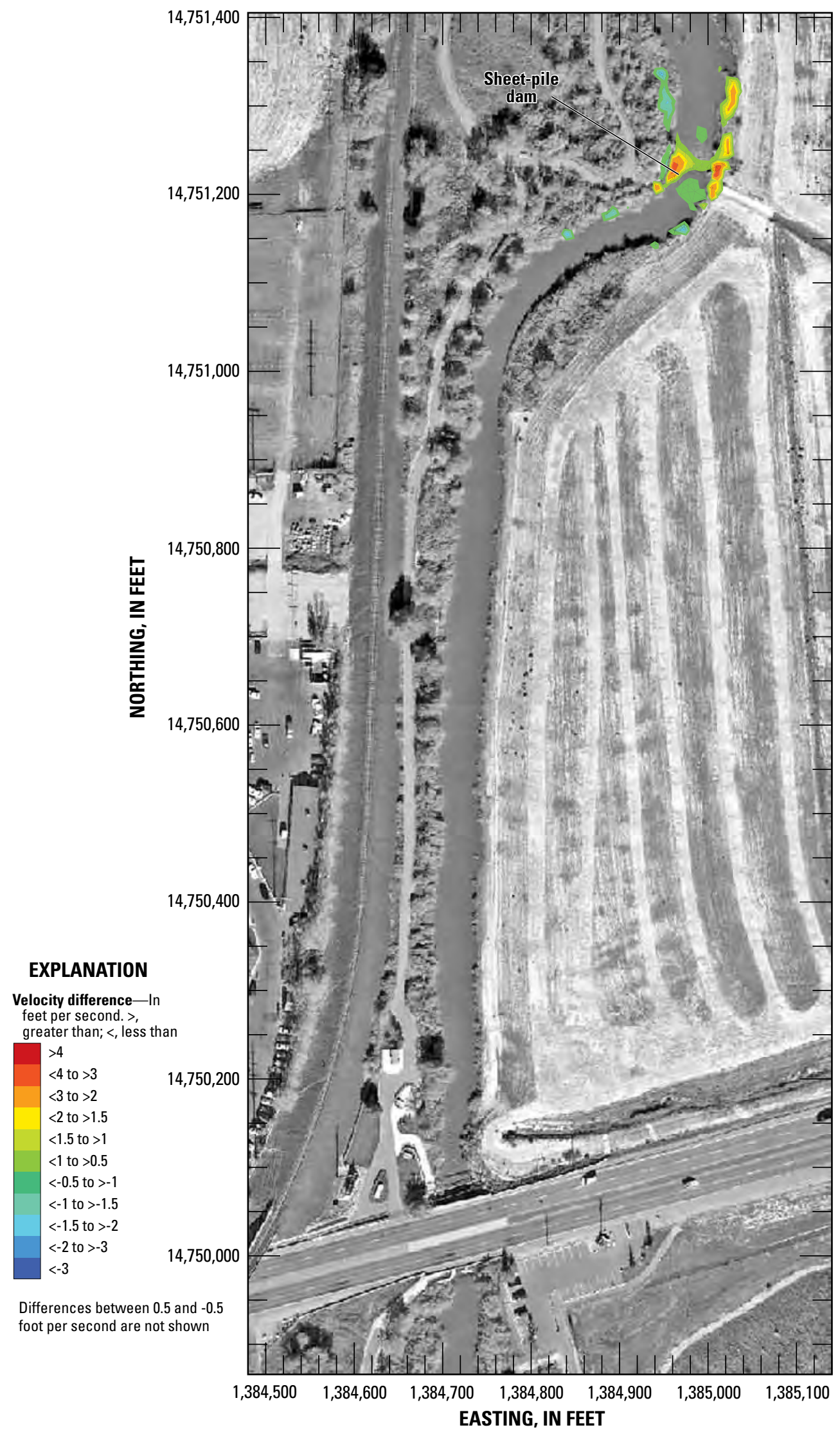

Figure 21. Predicted water velocities for the proposed replacement structure as designed minus predicted water velocities for the existing sheet-pile dam for a streamflow of 1,000 cubic feet per second. 


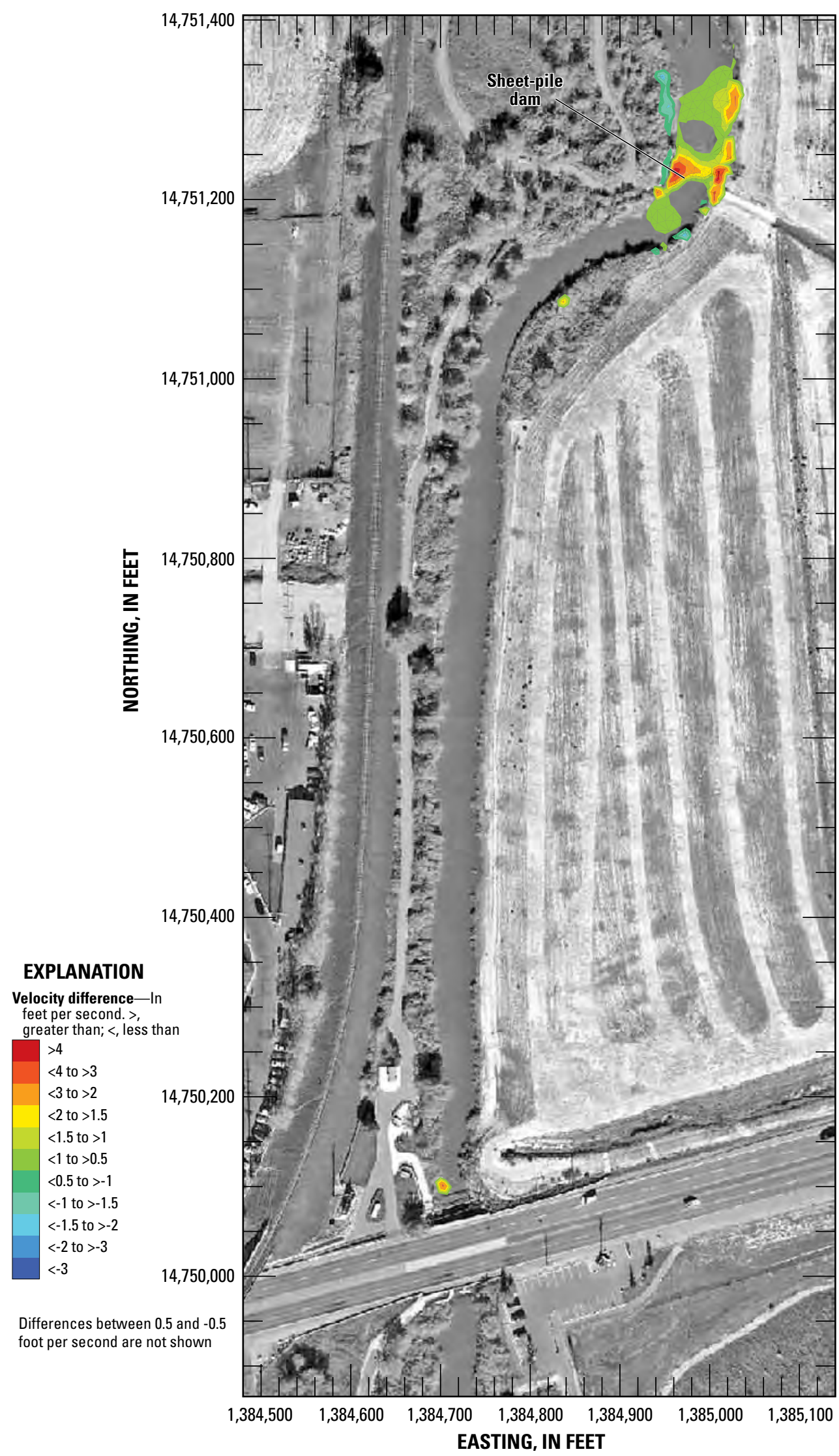

Figure 22. Predicted water velocities for the proposed replacement structure with an increased topography of 1.0 foot minus predicted water velocities for the existing sheet-pile dam for a streamflow of 1,000 cubic feet per second. 


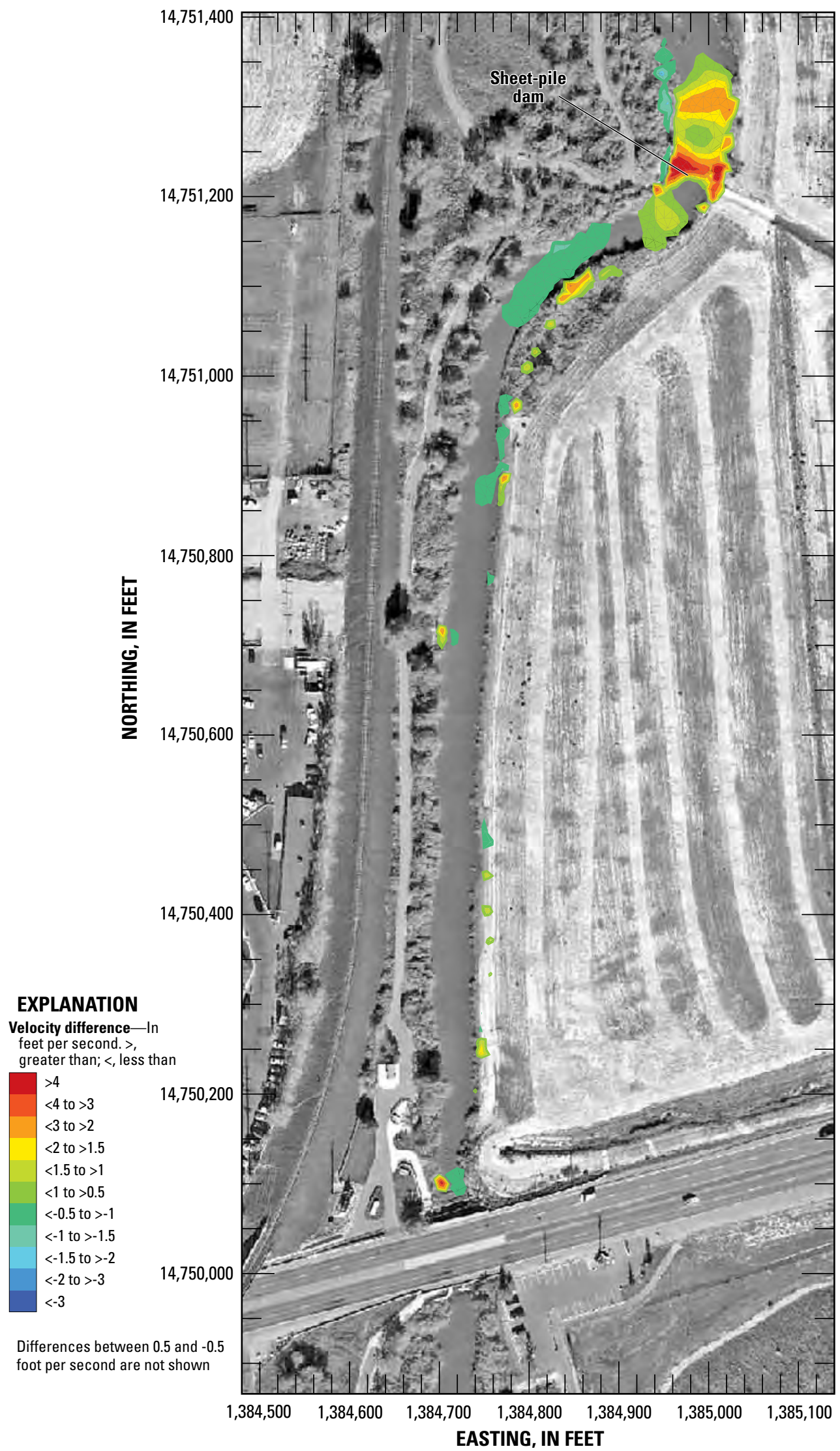

Figure 23. Predicted water velocities for the proposed replacement structure with an increased topography of 2.0 feet minus predicted water velocities for the existing sheet-pile dam for a streamflow of 1,000 cubic feet per second. 


\section{Hydraulic Characteristics of the Entire Study Reach}

Predicted water-surface elevations and velocities throughout the entire 2.5-mi reach for the two simulated streamflows $\left(1,040 \mathrm{ft}^{3} / \mathrm{s}\right.$ and $\left.2,790 \mathrm{ft}^{3} / \mathrm{s}\right)$ were provided by the FaSTMECH model. From the predicted velocities, boundary shear-stress values were computed throughout the reach as well. Predicted water-surface elevations, velocities, and computed shear stress were used by the USEPA in developing a series of channel bank stabilization designs that incorporated a variety of materials.

Predicted water-surface elevations, velocities, and computed boundary shear stress were mapped on an aerial photograph for the two simulated streamflows to place these parameters in a spatial context. Examples of these maps, one for each of the three parameters for the $2,790 \mathrm{ft}^{3} / \mathrm{s}$ simulation, are shown in figures 24-26. From these maps, locations showing elevated velocities, or boundary shear stress could be further examined. For example, some of the largest shear-stress values of the study reach were predicted to occur immediately downstream from the constructed replacement structure (fig. 27A). For this location, because of the larger shear-stress values, a rock riprap design was developed and constructed by the USEPA along the east bank to protect the geotechnical cap (fig. 27B).

The FaSTMECH model uses a curvilinear grid of streamwise and cross-stream node strings to define the modeling domain. If the centerline of the grid follows the course of the river, cross-stream node strings are located generally perpendicular to the direction of flow (fig. 28). The curvilinear grid of the study reach FaSTMECH model did follow the course of the Jordan River and because of this, stream-wise profiles of predicted parameters such as the maximum and average cross-stream velocity along with the average crossstream water-surface elevation were able to be determined and examined graphically.

For the two simulated streamflows, the maximum predicted velocity was determined and the average velocity was computed along cross-stream node strings. These velocities for the simulated streamflows were plotted by the downstream distance of the Jordan River study reach (figs. 29 and 30) Similarly, average cross-stream water-surface elevations also were computed and plotted by downstream distance (fig. 31). Average channel-bed elevations, computed from predicted depths and average water-surface elevations along crossstream node strings for the simulated streamflow of 1,040 $\mathrm{ft}^{3} / \mathrm{s}$, also were plotted (fig. 31). The average depths for the smaller streamflow were used to compute the average channelbed elevations because there was little overbank flow for this streamflow in comparison with the streamflow of $2,790 \mathrm{ft}^{3} / \mathrm{s}$. For these plots it was desired that the average channel-bed elevations represent the elevation of the main channel and not be affected by the overbank flow which is much shallower. For reference, relevant locations and structures along the study reach are shown on the plots.
The general pattern of the cross-stream velocity throughout the study reach for streamflows of 1,040 and $2,790 \mathrm{ft}^{3} / \mathrm{s}$ are similar except at the 7800 South Bridge and the constructed sheet-pile dam replacement structure. At 1,040 $\mathrm{ft}^{3} / \mathrm{s}$, the velocity at the replacement structure is the greatest, with the geometry of the 7800 South Bridge predicted to cause a substantial increase in velocity compared with the velocities throughout the study reach. Interestingly, the predicted velocities at the 7800 South Bridge are the greatest in the study reach for the simulated streamflow of $2,790 \mathrm{ft}^{3} / \mathrm{s}$. The smaller velocities at the replacement structure for this streamflow are because of water predicted to bypass to the west of the replacement structure.

Similar to the cross-stream velocities, the water-surface profiles for the two streamflows are similar in form except at the 7800 South Bridge and at the constructed sheet-pile dam replacement structure. The extent of the backwater associated with both the 7800 South Bridge and the constructed sheet-pile replacement structure is evident in the predicted water-surface elevations for both streamflows (fig. 31). The replacement structure appears to cause a greater backwater effect for the streamflow of $1,040 \mathrm{ft}^{3} / \mathrm{s}$ than for the streamflow of $2,790 \mathrm{ft}^{3} / \mathrm{s}$. In contrast, the geometry of the 7800 South Bridge is predicted to cause a greater backwater effect for the streamflow of $2,790 \mathrm{ft}^{3} / \mathrm{s}$ than for the streamflow of $1,040 \mathrm{ft}^{3} / \mathrm{s}$.

\section{Limitations and Uncertainty}

This report documents the construction of SToRM models that were used to assess the hydraulic characteristics of the sheet-pile dam associated with the Midvale Slag Superfund Site and a proposed replacement structure. These SToRM models were neither calibrated nor verified by observed streamflows. Channel frictional characteristics for these models and the streamflows that each model simulated were equal, which provided a simplified means to compare the generated results. Users of the results generated by the SToRM models should understand that frictional characteristics associated with streambed materials often vary with depth and because of this, model predicted water-surface elevations and velocities may differ from actual water-surface elevations and velocities.

The proposed replacement structure, including the various topographic adjustments, that were examined with the SToRM model, was not constructed. A different type of structure was selected as the replacement for the sheet-pile dam by the USEPA and was not examined with the SToRM model prior to construction. This constructed structure was represented in the FaSTMECH study reach model.

The FaSTMECH study reach model was verified by observed water-surface elevations and velocities for a streamflow of $1,100 \mathrm{ft}^{3} / \mathrm{s}$. Channel roughness was computed using bed-material samples collected in the southern part of the study reach (Huffman and Carpenter, Inc., written commun., 2001) and model-predicted streamflow depths. The determined median, or D50, grain size from the bed-material 


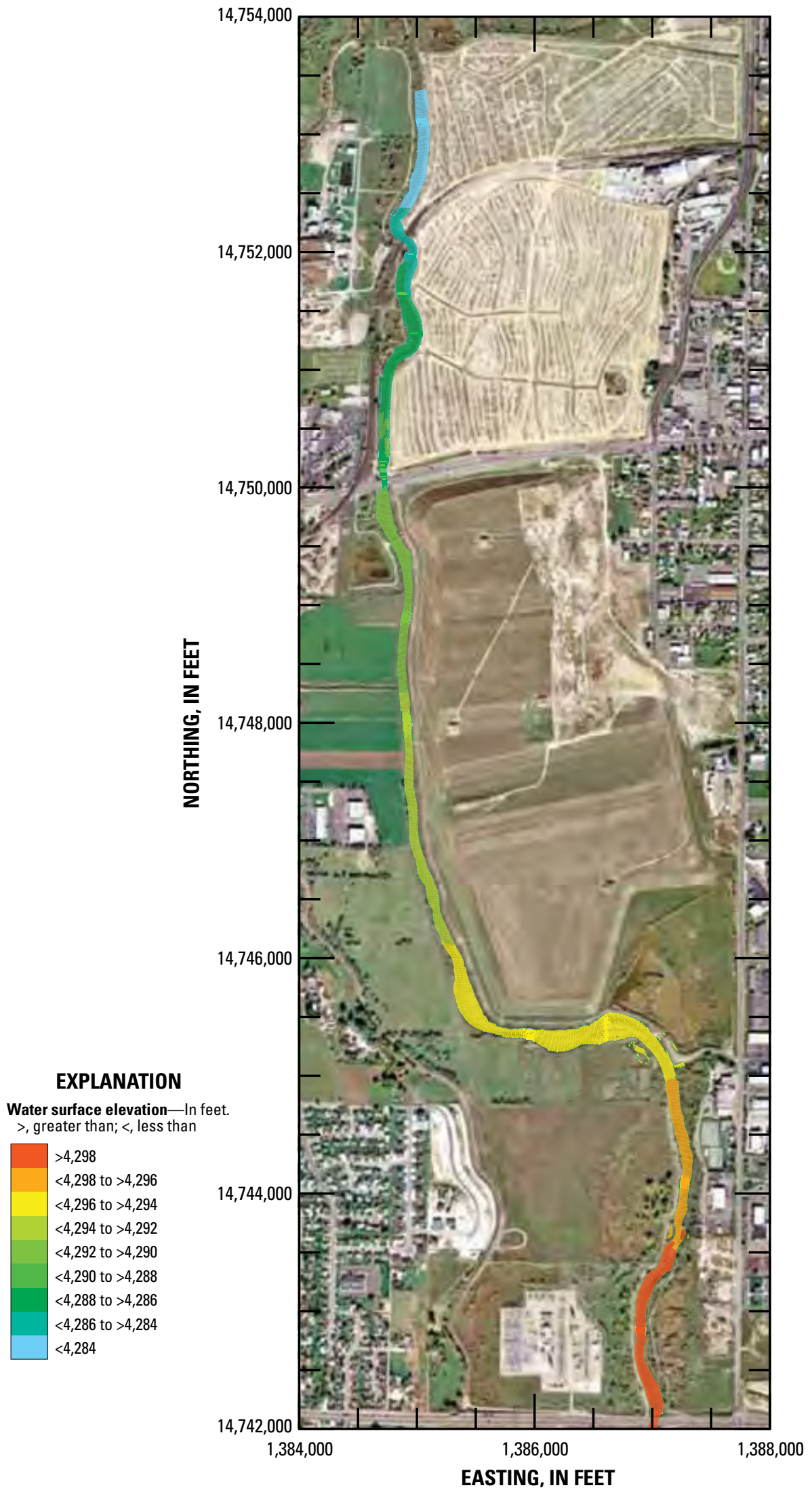

Figure 24. Predicted water-surface elevations throughout the study reach for a streamflow of 2,790 cubic feet per second. 


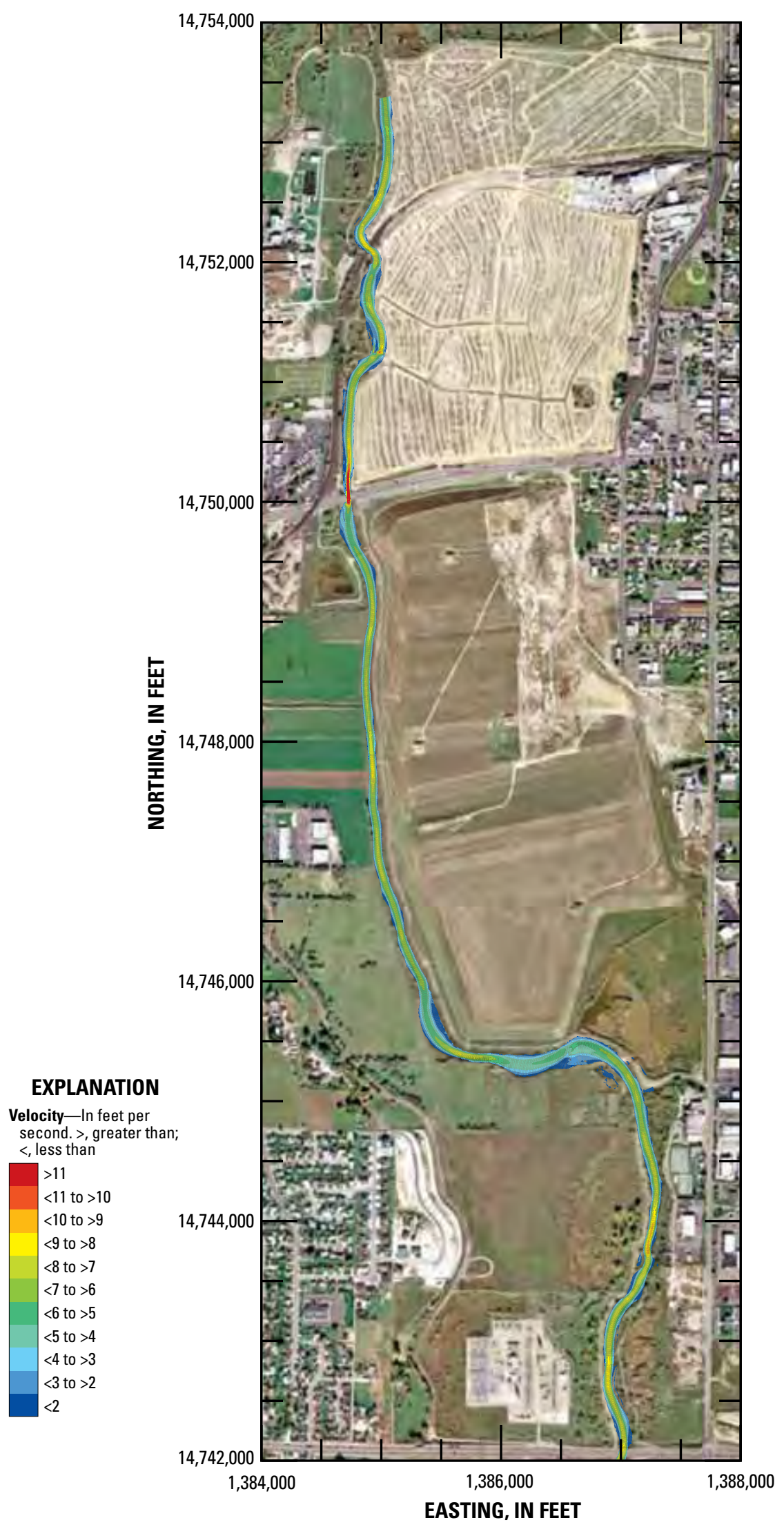

Figure 25. Predicted water velocities throughout the study reach for a streamflow of 2,790 cubic feet per second. 


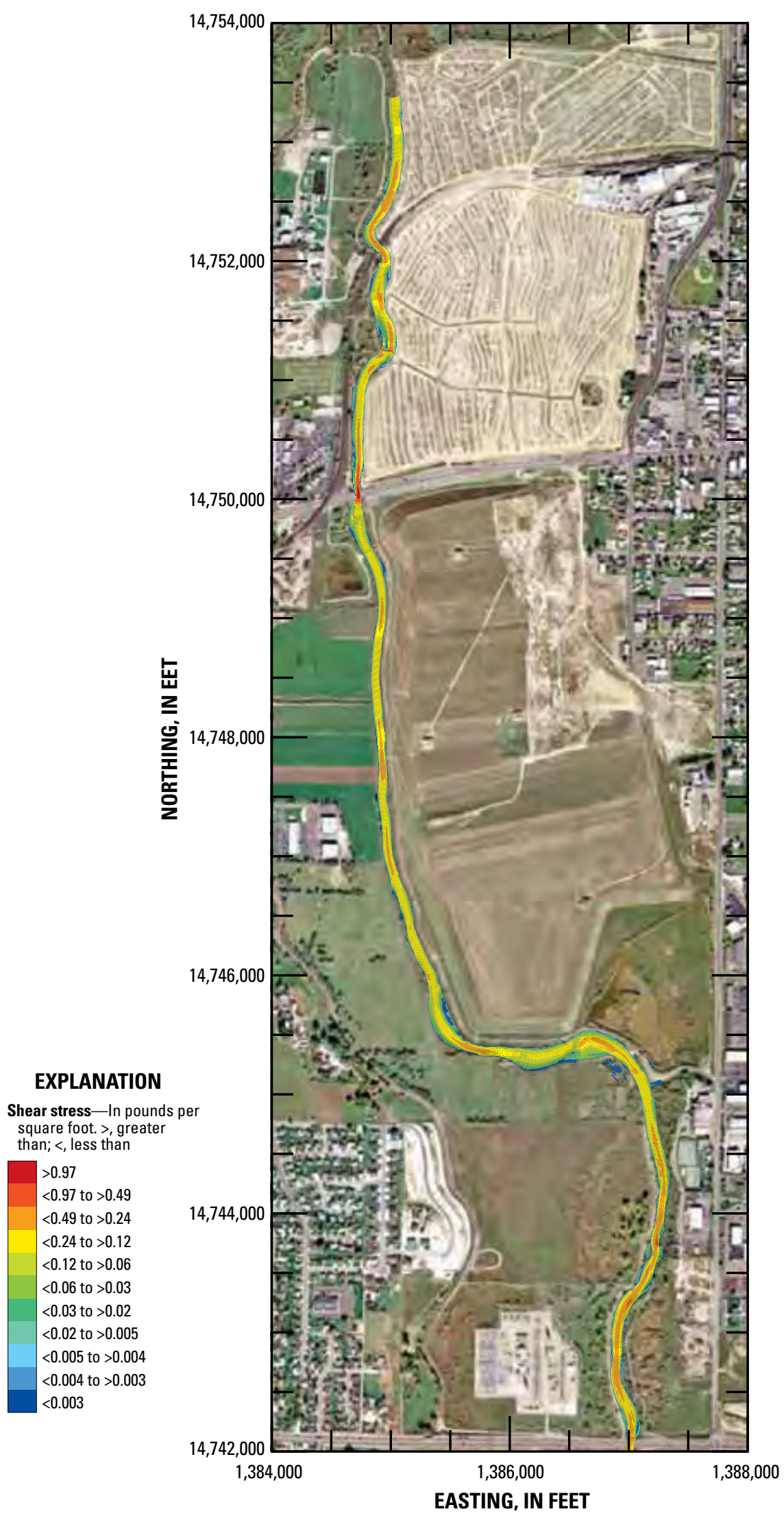

Figure 26. Predicted boundary shear stress throughout the study reach for a streamflow of 2,790 cubic feet per second. 
$\boldsymbol{A}$
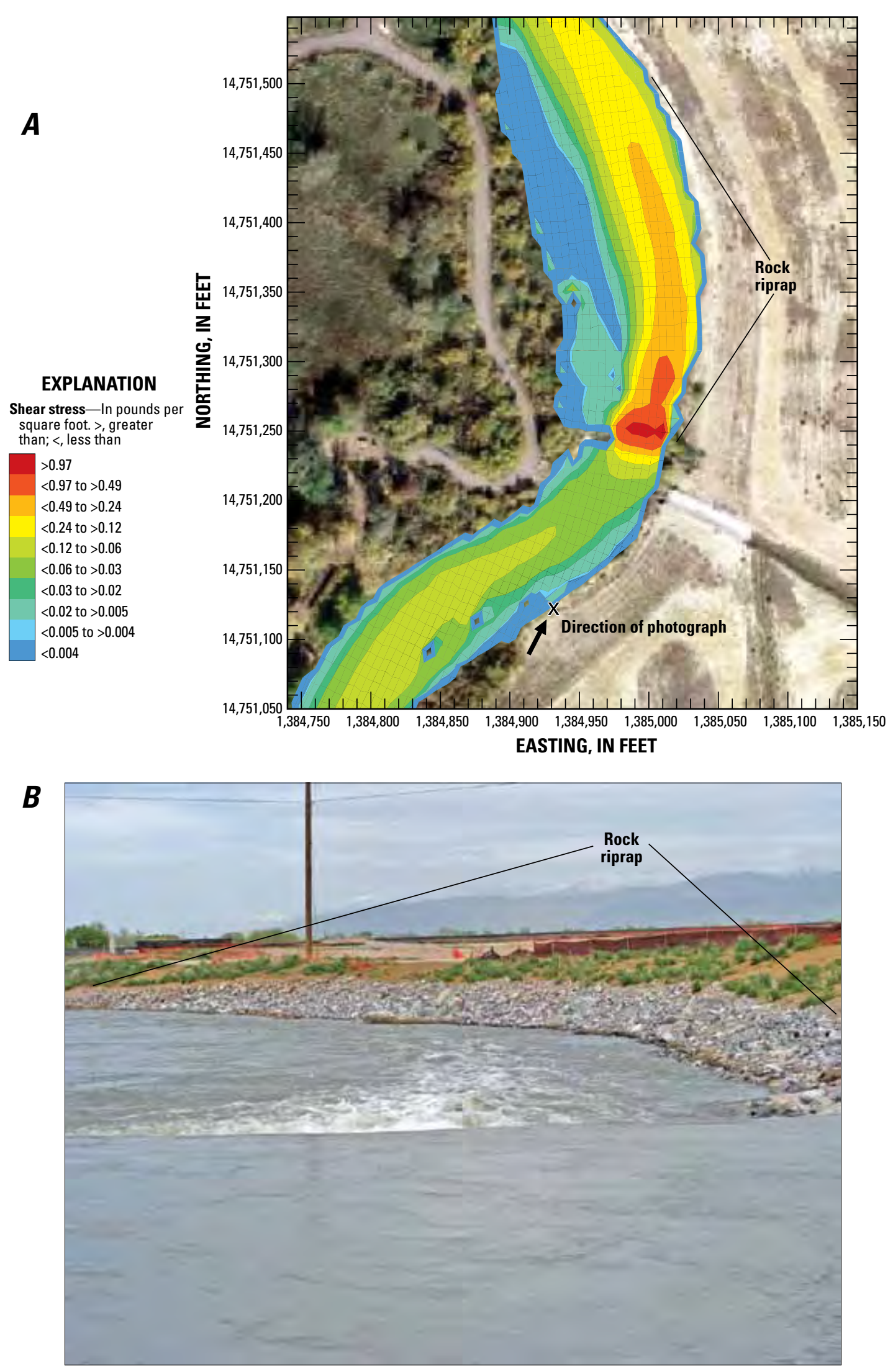

Figure 27. A, model predicted boundary shear stress near constructed sheet-pile dam replacement structure for a streamflow of 1,100 cubic feet per second. $B$, photograph taken upstream from constructed sheet-pile dam replacement structure looking downstream at rock riprap along east bank of Jordan River at a streamflow of 1,100 cubic feet per second. 


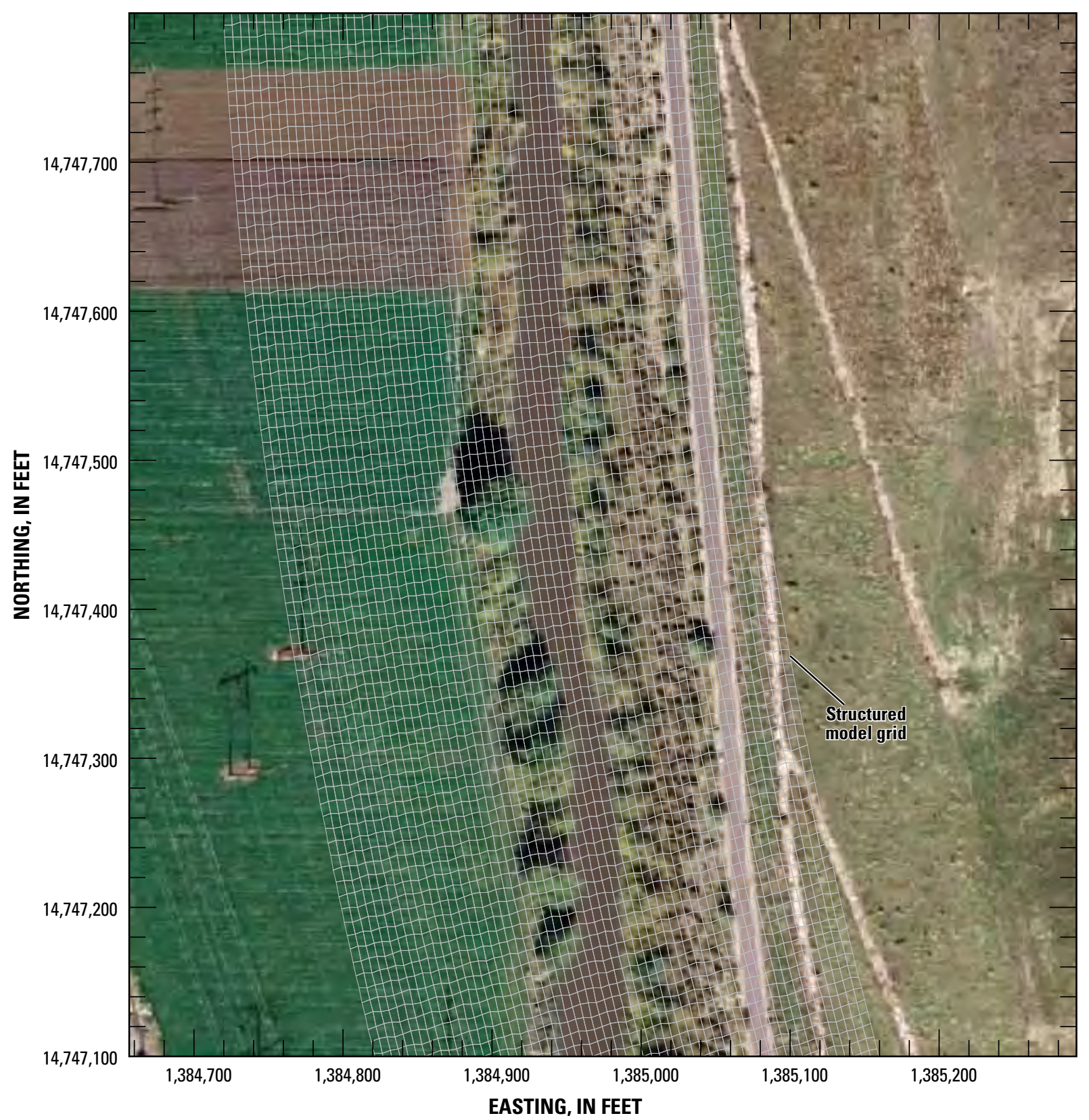

Figure 28. Close-up of structured curvilinear grid overlaid on an aerial photograph showing how the cross-stream node strings are perpendicular to the direction of flow. 


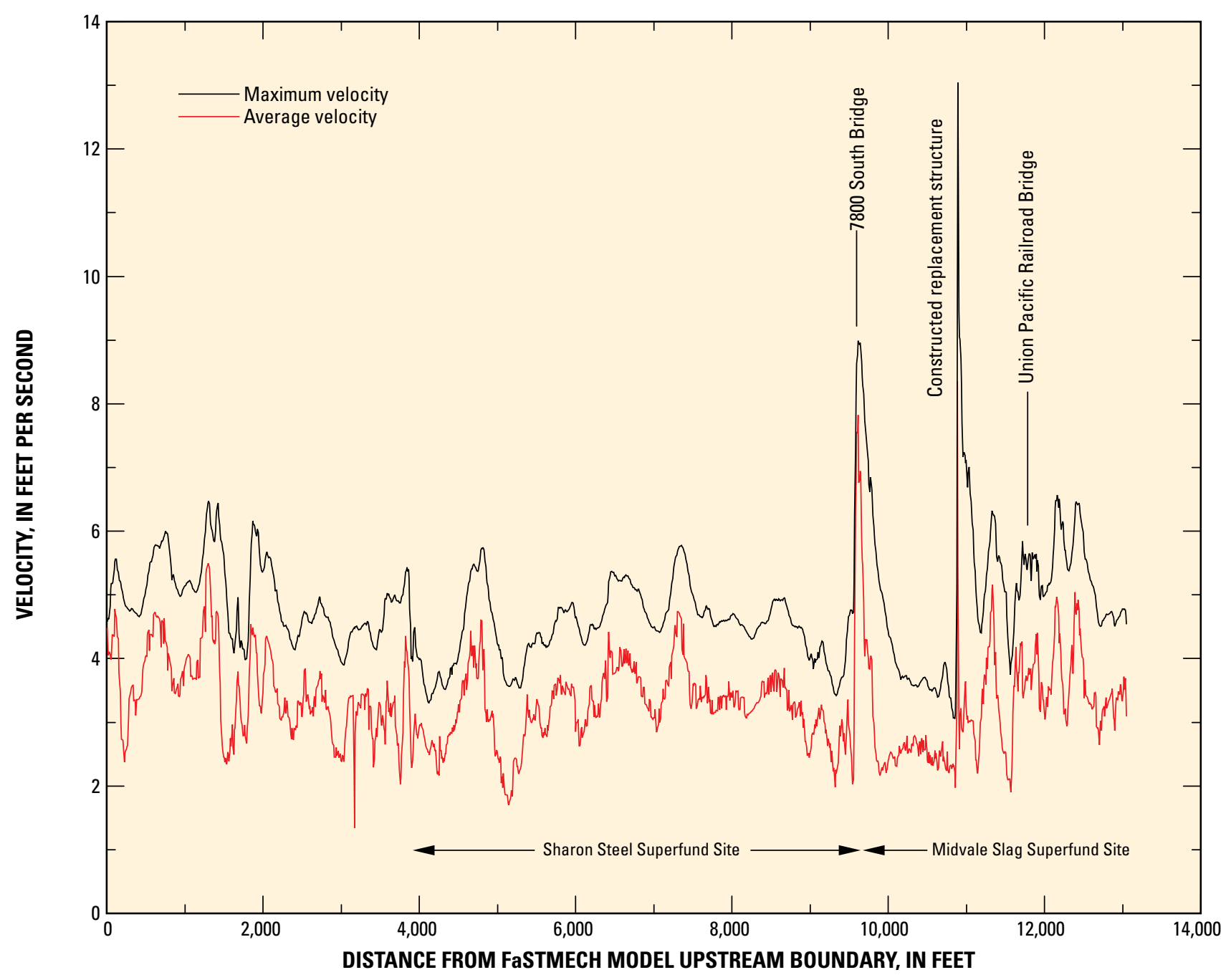

Figure 29. Downstream profile of predicted cross-stream maximum and average velocities for a streamflow of 1,040 cubic feet per second.

samples was assigned to the entire study reach. Actual bedmaterial sizes in the northern part of the study reach, and therefore channel roughness characteristics, may differ from those in the southern part of the study reach. When using the results generated by the FaSTMECH study reach model for a specific location in the study reach, users should examine the relation between observed and predicted water-surface elevations (fig. 10) and velocities (fig. 11) for that same location to assist in the assessment of uncertainty in the results.

The FaSTMECH model uses a structured curvilinear grid to define the modeling domain and because of this, the actual topography of the constructed replacement structure was not represented as accurately as it could have been using an unstructured grid such as that used by SToRM. The length of the study reach, together with the desired resolution of the results discouraged the use of a model that employs an unstructured grid, such as SToRM, because they are generally computationally less efficient than structured grid models, such as FaSTMECH. The objectives of the FaSTMECH model were to predict hydraulic characteristics throughout the study reach and were not specific to the hydraulic characteristics of the replacement structure.

\section{Summary}

The final remediation tasks of the Midvale Slag and Sharon Steel Superfund Sites adjacent to the Jordan River in Midvale and West Jordan, Utah, included (1) replacing a failing and dangerous historic sheet-pile dam with a new structure that possessed hydraulic characteristics amenable to protecting the mitigation efforts of the Midvale Slag Superfund Site, and (2) stabilizing the river banks adjacent to the Superfund sites. To assist with these tasks, two hydraulic modeling codes contained in the USGS Multi-Dimensional Surface-Water 


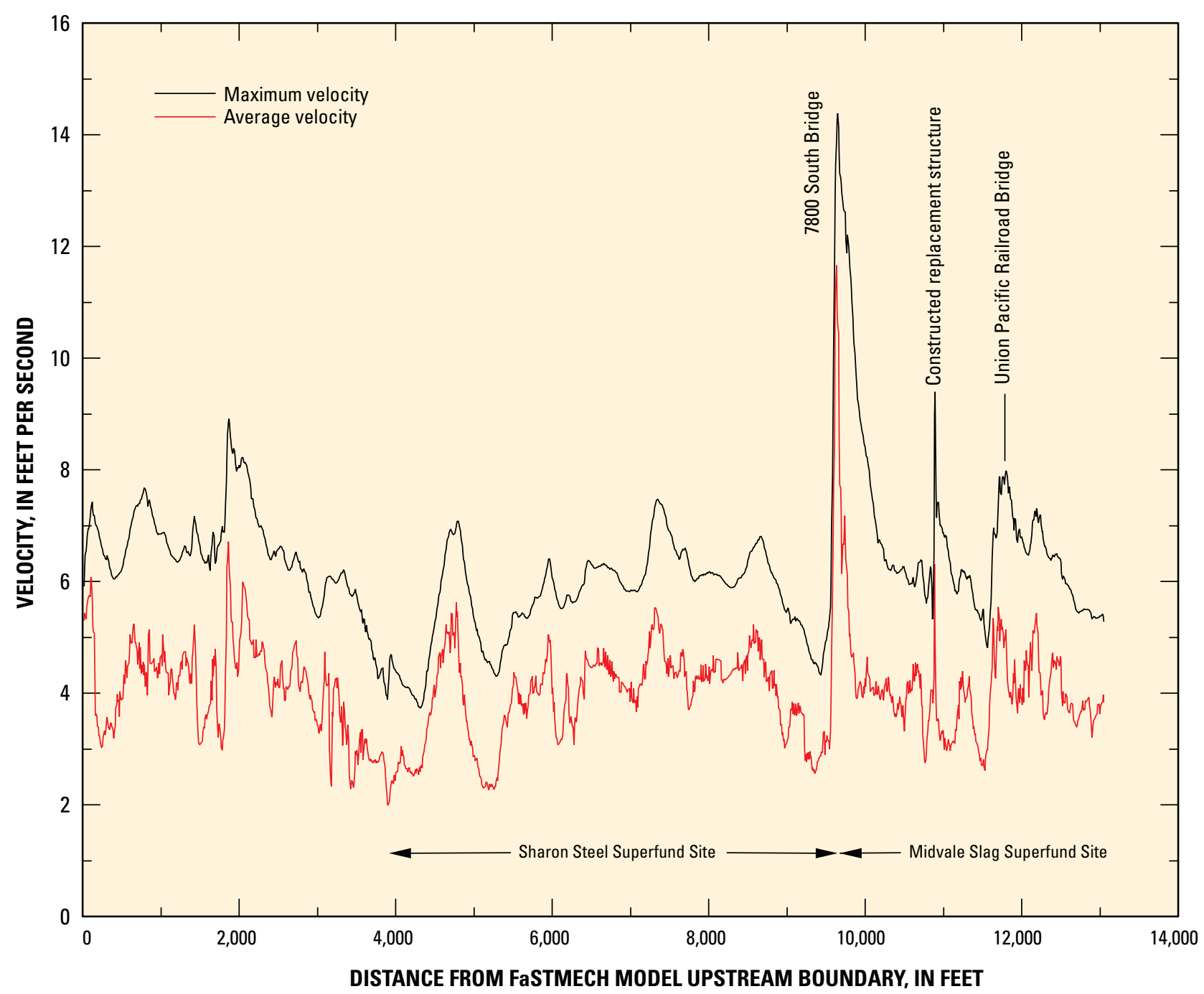

Figure 30. Downstream profile of predicted cross-stream maximum and average velocities for a streamflow of 2,790 cubic feet per second.

Modeling System (MD_SWMS), System for Transport and River Modeling (SToRM) and Flow and Sediment Transport and Morphological Evolution of Channels (FaSTMECH), were used to predict water-surface elevations, velocities, and boundary shear-stress values throughout the Jordan River study reach. The SToRM model of the 0.7 -mi subreach containing the sheet-pile dam provided a comparison of water-surface elevations and velocities between the existing sheet-pile dam and the proposed replacement structure. Difference maps indicated that the velocities associated with the proposed replacement structure topographies generally were less than or equal to those associated with the historic sheet-pile dam. Similarly, water-surface elevations associated with the proposed replacement structure topographies were all either greater than or equal to water-surface elevations associated with the sheet-pile dam. A FaSTMECH model of more than 90,000 nodes was developed for the entire study reach to aid engineers in bank stabilization designs. Predicted water-surface elevations, velocities, and shear-stress values were mapped on an aerial photograph of the study reach to place these parameters in a spatial context. Profile plots of predicted cross-stream maximum and average velocity for a streamflow of 1,040 cubic feet per second $\left(\mathrm{ft}^{3} / \mathrm{s}\right)$ show that the highest velocities are associated with the constructed sheet-pile replacement structure. Results also indicate that the geometry of the 7800 South Bridge causes more backwater and higher velocities than the constructed sheet-pile replacement structure for the larger simulated streamflow of $2,790 \mathrm{ft}^{3} / \mathrm{s}$. 


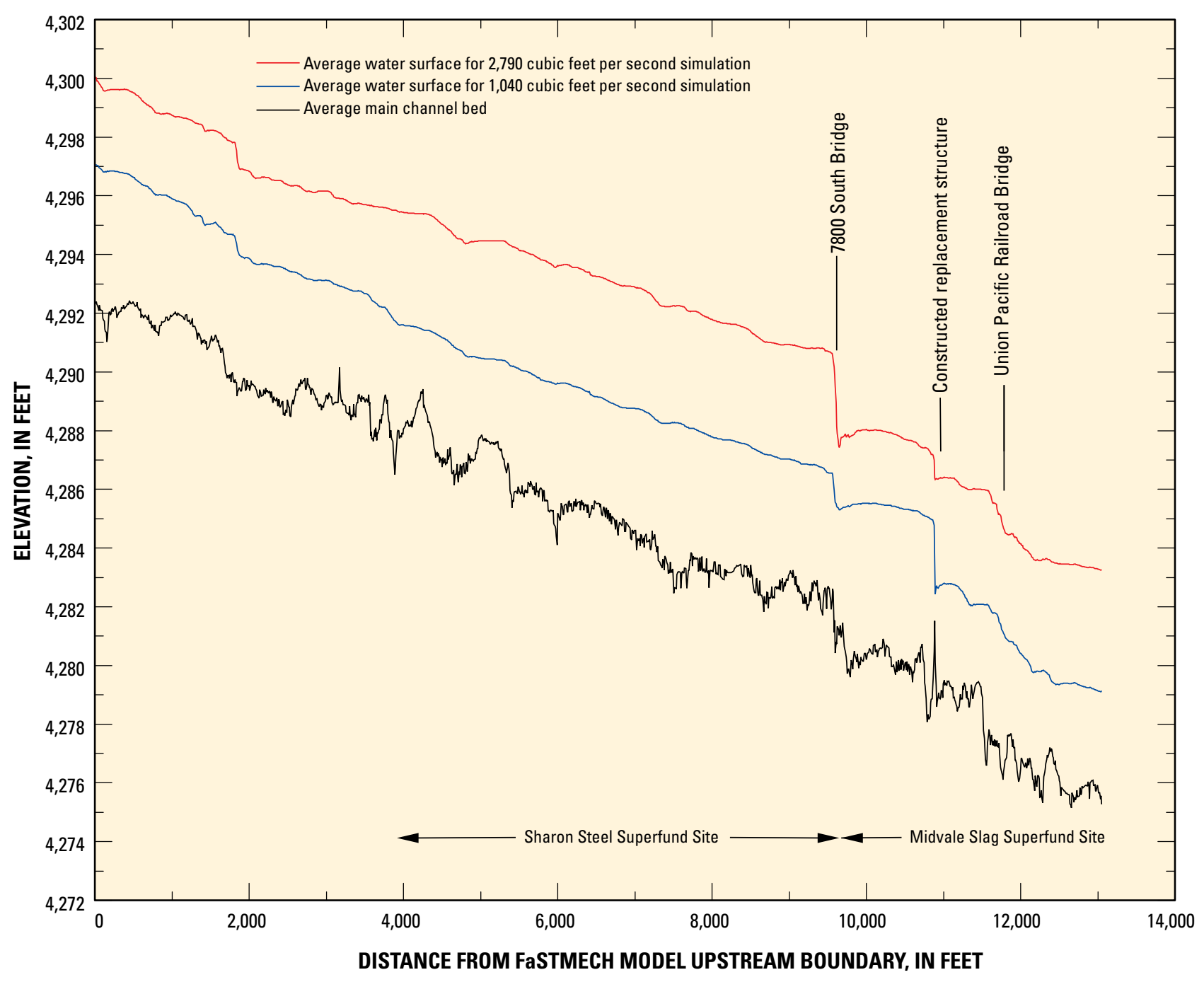

Figure 31. Downstream profile of predicted cross-stream average water-surface elevations for streamflows of 1,040 and 2,790 cubic feet per second. Average channel-bed elevations also are shown.

\section{References Cited}

Baily, J.F., and Ray, H.A., 1966, Definition of stage-discharge relation in natural channels by step-backwater analysis: U.S. Geological Survey Water-Supply Paper 1869-A, 24 p.

Barnes, H.H., Jr., 1967, Roughness characteristics of natural channels: U.S. Geological Survey Water-Supply Paper $1849,213 \mathrm{p}$.

Chow, V.T., 1959, Open-channel hydraulics: New York, McGraw-Hill, 680 p.

Federal Emergency Management Agency, 2003, Guidelines and specifications for flood hazard mapping partners, accessed June 1, 2008, at http://www.fema.gov/library/ viewRecord.do? $\mathrm{id}=2206$.
Hicks, D.M., and Mason, P.D., 1998, Roughness characteristics of New Zealand rivers: Christchurch, New Zealand, National Institute of Water and Atmospheric Research Ltd, 329 p.

Kenney, T.A., 2006, Verification of an uncalibrated twodimensional hydraulic model with velocity and remote imagery: Proceedings of the Third Federal Interagency Hydrologic Modeling Conference, April 2-6, 2006, Reno, Nevada, 9 p., accessed February 23, 2011, at http://acwi.gov/hydrology/mtsconfwkshops/conf_ proceedings/3rdFIHMC/6F_Kenney.pdf.

McDonald, R.R., Nelson, J.M., and Bennett, J.P., 2005, Multidimensional surface-water modeling system user's guide: U.S. Geological Survey Techniques and Methods, 6-B2, $136 \mathrm{p}$. 
National Geodetic Survey, 2004, GEOID03 model, accessed September 1, 2007, at http://www.ngs.noaa.gov/PC_PROD/ GEOID03/.

Phillips, J.V., and Ingersoll, T.L., 1998, Verification of roughness coefficients for selected natural and constructed stream channels in Arizona: U.S. Geological Survey Professional Paper 1584, $77 \mathrm{p}$.

Salt Lake County Flood Control, 2010, accessed May 2, 2010, at http://www.pweng.slco.org/flood/streamflow/index.cfm webpage reference.

Simões, F.J.M., 2009, SToRM: A numerical model for environmental surface flows, 33rd Congress of the International Association for Hydraulic Research, Vancouver, Canada, August 2009.

Trimble Navigation Limited, 2001, Trimble survey controller reference manual, Version 7.60, Revision A, Trimble Navigation Limited, Sunnyvale California, variously paged.

Utah Automated Geographic Reference Center, 2008, 2-meter Light Detection and Ranging elevation data, accessed January 2008, at http://gis.utah.gov/elevation-terrain-data/2meter-lidar. 


